\title{
Quantitative Property-Property Relationship for Screening-Level Prediction of Intrinsic Clearance of Volatile Organic Chemicals in Rats and Its Integration within PBPK Models to Predict Inhalation Pharmacokinetics in Humans
}

\author{
Thomas Peyret and Kannan Krishnan \\ Département de Santé Environnementale et Santé au Travail, Université de Montréal, C.P. 6128, Succursale Centre-Ville, Montréal, \\ QC, Canada H3C $3 J 7$
}

Correspondence should be addressed to Kannan Krishnan, kannan.krishnan@umontreal.ca

Received 31 October 2011; Revised 13 January 2012; Accepted 13 January 2012

Academic Editor: Jane C. Caldwell

Copyright (C) 2012 T. Peyret and K. Krishnan. This is an open access article distributed under the Creative Commons Attribution License, which permits unrestricted use, distribution, and reproduction in any medium, provided the original work is properly cited.

The objectives of this study were (i) to develop a screening-level Quantitative property-property relationship (QPPR) for intrinsic clearance $\left(\mathrm{CL}_{\text {int }}\right)$ obtained from in vivo animal studies and (ii) to incorporate it with human physiology in a PBPK model for predicting the inhalation pharmacokinetics of VOCs. $\mathrm{CL}_{\text {int }}$, calculated as the ratio of the in vivo $V_{\max }(\mu \mathrm{mol} / \mathrm{h} / \mathrm{kg}$ bw rat) to the $K_{m}(\mu \mathrm{M})$, was obtained for 26 VOCs from the literature. The QPPR model resulting from stepwise linear regression analysis passed the validation step $\left(R^{2}=0.8\right.$; leave-one-out cross-validation $\left.Q^{2}=0.75\right)$ for $\mathrm{CL}_{\text {int }}$ normalized to the phospholipid (PL) affinity of the VOCs. The QPPR facilitated the calculation of $\mathrm{CL}_{\text {int }}\left(\mathrm{L} \mathrm{PL} / \mathrm{h} / \mathrm{kg}\right.$ bw rat) from the input data on $\log P_{\text {ow }}, \log$ blood: water PC and ionization potential. The predictions of the QPPR as lower and upper bounds of the $95 \%$ mean confidence intervals (LMCI and UMCI, resp.) were then integrated within a human PBPK model. The ratio of the maximum (using $\mathrm{LMCI}$ for $\mathrm{CL}_{\text {int }}$ ) to minimum (using UMCI for $\mathrm{CL}_{\text {int }}$ ) AUC predicted by the QPPR-PBPK model was $1.36 \pm 0.4$ and ranged from 1.06 (1,1-dichloroethylene) to 2.8 (isoprene). Overall, the integrated QPPR-PBPK modeling method developed in this study is a pragmatic way of characterizing the impact of the lack of knowledge of $\mathrm{CL}_{\text {int }}$ in predicting human pharmacokinetics of VOCs, as well as the impact of prediction uncertainty of $\mathrm{CL}_{\text {int }}$ on human pharmacokinetics of VOCs.

\section{Introduction}

The evolving scientific and regulatory activities in Europe and North America emphasize the need for the development of tools that refine, replace, or reduce the use of animals and human volunteers in pharmacokinetic and toxicity tests [1-3]. The ability to base the toxic responses on the target tissue dose or internal concentration of the toxic moiety of the chemicals is key to the predictive tools reflective of the current state of science. Therefore, physiologically based pharmacokinetic (PBPK) models that are capable of providing a priori prediction of the time course of chemicals in blood and tissues is of tremendous interest [4]. PBPK models are mechanistically based mathematical descriptions of the absorption, distribution, metabolism, and excretion of chemicals or pharmaceutical compounds. In PBPK models, the organism is represented as a set of several tissue compartments interconnected by blood flows. In these models, the internal dose measures (e.g., blood or tissue concentrations, amount metabolized) of a chemical are described on the basis of mass-balance differential equations requiring species-specific properties (e.g., alveolar ventilation rate, cardiac output, regional blood flows, and tissue volumes) and chemical-specific input parameters (e.g., partition coefficients and metabolic constants). Although the species-specific values of several physiological parameters are available in the literature [4-6], the partition coefficients (PCs) and metabolic constants need to be determined 
experimentally or calculated by using animal-replacement methods for each chemical individually [7]. The values of tissue : blood or tissue: plasma partition coefficients essential for developing PBPK models have been estimated for a wide range of chemicals and chemical classes, including drugs, with the use of tissue composition-based algorithms or QSAR methods (e.g., [8-19]).

Regarding the metabolism parameters (i.e., hepatic clearance, intrinsic clearance, $V_{\max }, K_{m}, K_{\text {cat }}$, free energy of binding, energy of activation, or activation enthalpy), some studies have developed 2-D and 3-D QSARs but with a specific focus on either a single isozyme, a single reaction or a single class of substances $[8,20-38]$. None of these past efforts succeeded in predicting both $V_{\max }$ and $K_{m}$ (or $C L_{\text {int }}$ ) of environmental chemicals for direct incorporation within animal or human PBPK models. Alternatively, few studies utilized the group contribution method of Gao [39-43], to predict metabolic rates for PBPK models. In this method, the chemical is decomposed into different structural fragments or groups, the contributions of which are obtained by regression analysis [39]. Accordingly, these publications demonstrated the feasibility of developing structure-property relationships for the metabolism rates. The group contribution method was successfully used to develop quantitative structure-property relationships (QSPRs) for the tissue: air partition coefficients as well as intrinsic $\left(C L_{\text {int }}\right)$ and hepatic clearance $\left(C L_{h}\right.$ for a group of low-molecular-weight volatile organic chemicals (VOCs) in rats $[41,42]$. These QSPR models, in turn, were incorporated within PBPK models to predict reasonably well the blood kinetics of inhaled VOCs in rats. As these QSPRs are species specific, they could not be used to conduct interspecies extrapolations. To overcome this limitation, Béliveau et al. [40] developed biologically based algorithms for PCs and $C L_{h}$ to conduct rat to human extrapolations of the inhalation toxicokinetics of VOCs. In this study, QSPRs based on the group contribution method were developed for the chemical-specific input parameters of the biological algorithms for PCs (i.e., oil : air, water : air,and blood protein : air) and $C L_{\text {int }}$ (intrinsic clearance normalized for cytochrome P450 2E1 content). More recently, QSPRs were developed for the metabolic constants $V_{\max }$ (maximum velocity of reaction) and $K_{m}$ (Michaelis constant) [43] and were further incorporated within a rat PBPK model to predict the toxicokinetics of mixtures of VOCs. Despite the successful use of the group contribution method in QSPR modeling of metabolism rates, their principal limitation relates to the fact that the chemical space they cover is extremely limited (low-molecular-weight VOCs containing one or more of the following fragments: $\mathrm{CH}_{3}, \mathrm{CH}_{2}, \mathrm{CH}$, $\mathrm{C}, \mathrm{C}=\mathrm{C}, \mathrm{H}, \mathrm{Br}, \mathrm{Cl}, \mathrm{F}$, benzene ring, and $\mathrm{H}$ on benzene ring). More experimental data on diverse chemicals would be needed to determine the contributions of other molecular fragments, as has been done with $P_{\text {ow }}$ (e.g., estimation of the contribution of 130 fragments (i.e., groups) required 1200 measurements of $P_{\text {ow }}$ ) [44]. To extend the currently available QSPR for $C L_{\text {int }}$ to cover more diverse fragments and at the same time respect a reasonable ratio of the number of parameters to the number of observations, extensive experimental data would be required.
Since the critical limitation in the construction of PBPK models for new substances continues to be the metabolism rate, a pragmatic approach-particularly for inhaled VOCs-is to evaluate the maximum and minimum possible blood concentration profiles in exposed individuals. Thus, using a hepatic extraction ratio $(E)$ of 0 and 1 in the PBPK models, Poulin and Krishnan [45] obtained simulations of the physiological limits (i.e., maximal and minimal blood concentration profiles) for inhaled VOCs in humans. Assuming the conceptual PBPK model and the values of its physiological parameters are reliable, the real answer, that is, the actual concentrations and kinetic curve, would be somewhere in between the theoretical limits simulated with these PBPK models [45]. The uncertainty associated with these theoretical bounds can be reduced by developing better estimates of the metabolism constants. This could be done, at a practical level, by developing in silico tools that provide a range of plausible values, in lieu of a single accurate point estimate. Such a tool might be of use for the toxicokinetic screening of substances, until the time when the chemical-specific measurements are obtained in vivo, in vitro, or with a highly precise mechanistic in silico method.

Since human exposures to environmental contaminants in most cases do not attain levels that approach or exceed saturation, it is not crucial to predict $V_{\max }$ and $K_{m}$ separately, particularly for simulating kinetics in humans exposed to low atmospheric concentrations of VOCs. Therefore, the availability of in silico approaches based on easily available parameters to predict plausible range of $C L_{\text {int }}$ would be desirable as a screening-level tool. The objective of this study was therefore to develop a quantitative propertyproperty relationship (QPPR) model of animal data to generate initial estimates (or bounds) of intrinsic clearance of VOCs, for eventual incorporation within a human PBPK model to simulate blood concentration profiles associated with inhalation exposures. In this regard, we focused on evaluating the impact of the uncertainty associated with QPPR predictions of $C L_{\text {int }}$ on the blood kinetics of VOCs in humans, relative to that of the uncertainty associated with the total lack of knowledge of the metabolic rate in humans. Furthermore, the reliability of applying the QPPR to predict the area under the blood concentration versus time curve (AUC) of parent chemicals was evaluated, as a function of the sensitivity of the metabolism parameter in the PBPK model and the prediction uncertainty of QPPR model.

\section{Methods}

A QPPR model for $C L_{\text {int }}$ was developed using a calibration set of 26 VOCs. The QPPR predictions were then compared with experimental data for several VOCs and the pharmacokinetics in humans were simulated using integrated QPPRPBPK models for these 26 VOCs. The predictions of QPPR were evaluated further with an external data set of $C L_{\text {int }}$ for 11 VOCs. 


\subsection{QPPR Modeling for Intrinsic Clearance}

2.1.1. Chemicals and Data Sources. The development of a global QPPR model for metabolism was initially undertaken using experimental data on the in vivo intrinsic clearance of 26 VOCs in rats, collated and evaluated in previous studies by Béliveau et al. [40, 41] (1,1,1,2-tetrachloroethane; 1,1,2,2-tetrachloroethane; 1,1,2-trichloroethane; 1,1dichloroethane; 1,1-dichloroethylene; 1,2-dichloroethane; benzene; bromochloromethane; bromodichloromethane; carbon tetrachloride; chloroethane; chloroform; cis-1,2dichloroethylene; dibromomethane; dichloromethane; ethylbenzene; hexachloroethane; isoprene; methyl chloride; $m$-xylene; $n$-hexane; pentachloroethane; styrene; toluene; trichloroethylene; vinyl chloride) [24, 46-53].

Subsequently, the resulting QPPR model was evaluated with experimental in vivo data on $C L_{\text {int }}$ for 11 additional VOCs in rats (1,1,1-trichloroethane; 1,2,4-trimethylbenzene; bromoform; dibromochloromethane; furan; halothane; $o$-xylene; trans-1,2-dichloroethylene; tetrachloroethylene; propylene; ethylene) $[46,48,54-61]$. These 11 chemicals outside the calibration set were also lipophilic, lowmolecular-weight VOCs and likely substrates of cytochrome P450 2E1 [32, 62]. Moreover except for halothane and 1,2,4trimethylbenzene, the chemicals of the evaluation dataset possess values of $P_{\text {ow }}$, ionization potential, and blood: water PC within the range of values for the chemicals in the QPPR calibration set.

2.1.2. Modeling Endpoint. For QPPR modeling, $C L_{\text {int }}$ (expressed in units of $\mathrm{L}$ blood, $C L_{\text {intblood, }}$ or $\mathrm{L}$ phospholipids, $C L_{\text {intPL }}$ ) was used as the endpoint. Initially, $C L_{\text {intblood }}\left(\mathrm{L}\right.$ blood $/ \mathrm{h} / \mathrm{kg}^{0.75}$ ) for all the studied chemicals was computed as allometrically scaled $V_{\max }\left(\mu \mathrm{mol} / \mathrm{h} / \mathrm{kg}^{0.75}\right) / K_{m}$ ( $\mu \mathrm{mol} / \mathrm{L}$ blood). Since CYPs are located in the endoplasmic reticulum embedded in the phospholipidic bilayer [63], the $C L_{\text {intPL }}$ values reflecting chemical affinity for the phospholipids (PL) were subsequently computed. The values of $C L_{\text {intPL }}$ ( $\mathrm{L}$ phospholipid $/ \mathrm{h} / \mathrm{kg}^{0.75}$ ) were obtained by dividing $V_{\max }\left(\mu \mathrm{mol} / \mathrm{h} / \mathrm{kg}^{0.75}\right)$ with $K_{m}$ expressed as $\mu \mathrm{mol} / \mathrm{L}$ PL. The $K_{m}$ values in $\mu \mathrm{M}$ of PL were obtained by multiplying the values of $K_{m}$ expressed as $\mu \mathrm{mol} / \mathrm{L}$ blood with the chemicalspecific phospholipid:blood partition coefficients $\left(P_{\mathrm{plb}}\right)$ calculated as follows:

$$
P_{\mathrm{plb}}=\frac{0.3 \cdot P_{\mathrm{oa}}+0.7 \cdot P_{\mathrm{wa}}}{P_{\mathrm{ba}}},
$$

where $P_{\text {oa }}$ is the $n$-octanol: air PC, $P_{\text {wa }}$ the water : air PC, and $P_{\mathrm{ba}}$ the blood: air PC.

The above equation computes $P_{\mathrm{plb}}$ as the ratio of phospholipid : air to blood: air PCs of the VOCs, based on Poulin and Krishnan [10, 12].

2.1.3. Input Parameters for Transforming the Endpoint. The input parameters required for converting the $C L_{\text {int }}$ obtained from the literature were $P_{\mathrm{oa}}, P_{\mathrm{wa}}$, and $P_{\mathrm{ba}}$.

(1) $P_{o a}$ and $P_{w a}$. The $n$-octanol: air PC $\left(P_{\text {oa }}\right)$, was calculated as the product of the $n$-octanol: water PC $\left(P_{\text {ow }}\right)$ and $P_{\text {wa }}$ (inverse of Henry's law constant at $37.5^{\circ} \mathrm{C}$ ). The values of $P_{\text {ow }}$ and $P_{\text {wa }}$ were predicted using U.S. EPA's freeware EPISUITE (http://www.epa.gov/opptintr/exposure/pubs/episuite.htm).

(2) $P_{b a}$. Experimental values were used for rat blood : air [54, $56,59,64-68]$. The calculated values of $P_{\mathrm{plb}}$ for the chemicals used for the development and for the evaluation of the QPPR are reported in Table 1.

2.1.4. Variable Selection. A priori list of variables was developed on the basis on mechanistic considerations. The rate and affinity for P450-mediated metabolism would appear to be related to the size, shape, charge, and energy of the substrate; therefore variables that reflect these properties were chosen for the QPPR analysis $[21,23,27,28,32,69-$ 71]. The descriptors of the size and shape of the molecule were the molecular length, width, depth, volume, surface, and the Kappa 2 index [72], as well as two descriptors used in the work of Lewis et al. [23], namely, the ratio of the molecular length to the molecular width $(\mathrm{L} / \mathrm{W})$ and the ratio of the area of the molecule (i.e., length times width) to the square of the depth $\left(a / d^{2}\right)$. The dipole moment and ionization potential (IP) were used as measure of the charge disposition and the energy in the molecule, respectively. The values of all the previously cited descriptors were calculated using commercially available software (Molecular Modeling Pro, Chem SW, Fairfield, CA). Before calculating the molecular descriptors with Molecular Modeling Pro, the 3D molecules were drawn and minimized using the full MM2 (molecular mechanics program) method provided in the software. The dipole moment and the ionization potential were calculated using MOPAC/PM3 program, included in Molecular Modeling Pro.

Hydrophobic descriptors such as $\log P_{\text {ow }}$ (log of the $n$ octanol: water PC) that reflect hydrogen bonding and $\pi$ $\pi$ stacking have already been correlated to the values of metabolic constants [69-71]. In this study, the following physicochemical parameters were chosen to describe the relative solubility and partitioning into diverse biological media: $\log P_{\text {ow }}, \log$ phospholipid: water PC $\left(\log P_{\text {plw }}\right)$; $\log$ blood: water PC $\left(\log P_{\mathrm{bw}}\right)$, and $\log$ water: air PC $\left(\log P_{\mathrm{wa}}\right)$. The blood: water and phospholipid: water PCs were obtained by dividing the blood:air and phospholipid: air PCs values by the water: air PC values. The values of $P_{\text {ow }}, P_{\text {wa }}$, blood:air, and phospholipid:air PCs were obtained as described for the calculation of $P_{\mathrm{plb}}(1)$.

2.1.5. Statistical Analysis. Multilinear regression analysis approach was chosen for the QPPR analysis of $C L_{\text {int }}$ because linear regression models are simple, transparent, and easy to reproduce [73]. The regression analysis was performed using SPSS v16 for Windows (SPSS Inc., Chicago, IL). Stepwise regression analysis was performed to select the QPPRs based on the most statistically significant independent variable(s) from an a priori list (see Section 2.1.4). The coefficient of determination $R^{2}$, the adjusted $R^{2}\left(R_{\mathrm{adj}}^{2}\right.$; adjusted for number of variables) [73], the standard error of the estimate $s$, and the value and significance of the $F$ statistic were calculated. The 
TABLE 1: Partition coefficients used in the human PBPK models.

\begin{tabular}{|c|c|c|c|c|c|c|c|}
\hline \multirow{2}{*}{ Chemicals $^{\mathrm{a}}$} & \multicolumn{6}{|c|}{ Partition coefficient $(\mathrm{PC})^{\mathrm{b}}$} & \multirow[t]{2}{*}{ Reference } \\
\hline & $P_{\mathrm{ba}}$ & $P_{\mathrm{lb}}$ & $P_{\mathrm{rb}}$ & $P_{\mathrm{pb}}$ & $P_{\mathrm{fb}}$ & $P_{\mathrm{plb}}$ & \\
\hline Benzene & 8.19 & 2.08 & 2.08 & 1.26 & 60.93 & 4.55 & {$[66]$} \\
\hline Bromochloromethane & 10.4 & 2.81 & 2.81 & 1.07 & 31.5 & 2 & {$[66,77]$} \\
\hline Bromodichloromethane & 26.6 & 1.15 & 1.15 & 0.47 & 19.77 & 2.48 & {$[78,79]$} \\
\hline Carbon tetrachloride & 2.73 & 5.2 & 5.2 & 1.67 & 131.5 & 8.57 & {$[66]$} \\
\hline Chloroethane & 2.69 & 1.34 & 1.34 & 1.2 & 14.3 & 4.42 & {$[66]$} \\
\hline Chloroform & 6.85 & 3.08 & 3.08 & 2.03 & 29.6 & 1.93 & {$[66]$} \\
\hline Dibromomethane & 19.9 & 3.42 & 3.42 & 2.03 & 39.8 & 1.78 & {$[66,77]$} \\
\hline Dichloroethane $(1,1-)$ & 4.94 & 2.19 & 2.19 & 1.04 & 33.2 & 4.27 & {$[66]$} \\
\hline Dichloroethane (1,2-) & 19.5 & 1.83 & 1.83 & 1.2 & 17.64 & 9.25 & {$[66]$} \\
\hline Dichloroethylene (1,1-) & 0.81 & 5.46 & 5.46 & 2.53 & 84.69 & 4.82 & {$[66,77]$} \\
\hline Dichloroethylene (cis-1,2) & 9.85 & 1.55 & 1.55 & 0.62 & 23 & 5.2 & {$[66]$} \\
\hline Dichloromethane & 9.7 & 1.46 & 1.46 & 0.82 & 12.4 & 1.79 & {$[80]$} \\
\hline Ethylbenzene & 28 & 2.99 & 2.15 & 0.93 & 55.6 & 13.2 & {$[67]$} \\
\hline Hexachloroethane & 52.4 & 7.04 & 7.04 & 1.43 & 63.4 & 156 & {$[66]$} \\
\hline Hexane $(n-)$ & 2.13 & 5.2 & 5.2 & 2.9 & 159 & 1.89 & {$[47]$} \\
\hline Isoprene & 0.75 & 2.57 & 2.45 & 1.97 & 82 & 11.84 & {$[52]$} \\
\hline Methyl chloride & 2.48 & 1.4 & 1.4 & 0.39 & 5.44 & 3.04 & {$[66]$} \\
\hline Pentachloroethane & 50.3 & 5.17 & 5.17 & 1.44 & 81.9 & 21.7 & {$[66,77]$} \\
\hline Styrene & 52 & 2.7 & 5.7 & 1 & 50 & 30.2 & {$[50]$} \\
\hline Tetrachloroethane $(1,1,1,2-)$ & 30.2 & 2.92 & 2.92 & 1.31 & 71.1 & 37.3 & {$[66]$} \\
\hline Tetrachloroethane $(1,1,2,2-)$ & 116 & 1.69 & 1.69 & 0.87 & 32.47 & 14.3 & {$[66]$} \\
\hline Toluene & 15.6 & 5.36 & 5.36 & 1.77 & 65.4 & 13.8 & {$[67]$} \\
\hline Trichloroethane (1,1,2-) & 35.7 & 2.05 & 2.05 & 0.64 & 40.3 & 10.1 & {$[66]$} \\
\hline Trichloroethylene & 8.11 & 3.35 & 3.35 & 1.24 & 68.3 & 5.73 & {$[66]$} \\
\hline Vinyl chloride & 1.16 & 1.38 & 1.38 & 1.81 & 17.2 & 4.87 & {$[66]$} \\
\hline Xylene $(m-)$ & 26.4 & 3.44 & 3.44 & 1.59 & 70.4 & 15.1 & {$[67]$} \\
\hline Bromoform & 102.3 & 2.06 & 2.06 & 1.12 & 40.4 & 2.44 & {$[78,79]$} \\
\hline Dibromochloromethane & 49.2 & 2.56 & 2.56 & 1.13 & 38.96 & 1.48 & {$[78,79]$} \\
\hline Dichloroethylene (trans-1,2-) & 6.04 & 1.48 & 1.48 & 0.58 & 24.5 & 11.7 & {$[66]$} \\
\hline Ethylene & 0.22 & 2.05 & 2.18 & 2.95 & 8.73 & 1.05 & {$[59]$} \\
\hline Furan & 6.59 & 0.9 & 0.9 & 0.64 & 9.72 & 2.75 & {$[56]$} \\
\hline Halothane & 3.3 & 2.42 & 2.42 & 2.91 & 44.2 & 5.82 & {$[58]$} \\
\hline Propylene & 0.44 & 1.09 & 1.2 & 1.25 & 11.7 & 1.52 & {$[54]$} \\
\hline Tetrachloroethylene & 10.3 & 5.88 & 5.88 & 3.1 & 119.1 & 11.1 & {$[57]$} \\
\hline Trichloroethane $(1,1,1-)$ & 2.53 & 1.24 & 3.4 & 3.4 & 103.9 & 21.7 & {$[48]$} \\
\hline Trimethylbenzene $(1,2,4-)$ & 85 & 4.4 & 4.4 & 2.11 & 109 & 19 & {$[61]$} \\
\hline Xylene (o-) & 34.9 & 3.09 & 3.09 & 1.47 & 53.8 & 22.6 & {$[66]$} \\
\hline
\end{tabular}

${ }^{a}$ Chemicals in italics were not included in the dataset for the calibration of the model.

${ }^{\mathrm{b}} P_{\mathrm{ba}}$ : blood: air PC; $P_{\mathrm{lb}}$ : liver blood PC; $P_{\mathrm{rb}}$ : richly perfused tissues:blood PC; $P_{\mathrm{pb}}$ : poorly perfused tissues: blood PC; $P_{\mathrm{fb}}$ : fat: blood PC; $P_{\mathrm{plb}}$ : phospholipids : blood PC.

normality of the residuals was checked visually on normal probability plots of the standardized residuals (i.e., expected normal cumulative probability versus observed cumulative probability). Leave-one-out cross-validation was conducted and the results were expressed in terms of $Q^{2}$, a measure of precision error of the model. The $Q^{2}$ was computed as follows [74]:

$$
Q^{2}=1-\frac{\text { PRESS }}{\text { SSY }}
$$


where PRESS is that predicted residual sum of squares and SSY the sum of squares of the response values. The statistical significance $(p<0.05)$ of the regression coefficients was estimated by a $t$ statistic test. Multicollinearity refers to the occurrence of correlation between two independent variables in the multiple linear regression model. Multicollinearity of the variables in the model was assessed by calculating the variance inflation factor (VIF) for all independent variables [75]. The value of VIF was calculated as follows [75]:

$$
\mathrm{VIF}_{i}=\frac{1}{1-R_{i}^{2}}
$$

where $\mathrm{VIF}_{i}$ is the variance inflation factor of the independent variable $i$ in the multilinear regression model and $R_{i}^{2}$ the coefficient of determination of the regression between the independent variable $i$ and the other independent variables in the multilinear regression model.

For each model, the application domain was documented by reporting the ranges of values of the descriptors, the modeled response, and the endpoint.

A QPPR model was considered adequate when: the values of $R^{2}$ and $R_{\text {adj }}^{2}$ were $\geq 0.6$ [73], the value of $Q^{2}$ was $\geq 0.6$ [76], and the independent variables were not highly correlated (i.e., VIF < 4) [75].

The predictions of the QPPR model were obtained in terms of lower and upper bounds of the 95\% mean confidence intervals (LMCI and UMCI, resp.) in order to represent the uncertainty associated with the mean predicted value. The LMCI and UMCI for the 11 VOCs, not in the QSPR calibration dataset, were obtained by adding them in the SPSS file containing the data used for the QPPR, along with the values of their independent variables only.

\subsection{Translation of QPPR Predicted Intrinsic Clearance Values} to In Vivo Metabolism Rate and Integration within Human PBPK Models. In the PBPK model, the value of intrinsic clearance was calculated as the product of the QPPR value of $C L_{\text {intPL }}\left(\mathrm{L}\right.$ of $\mathrm{PL} / \mathrm{h} / \mathrm{kg}^{0.75}$ ) and the phospholipid: blood PC (values of $P_{\mathrm{plb}}$ in Table 1). The intrinsic clearance ( $\mathrm{L}$ blood $/ \mathrm{h} / \mathrm{kg}^{0.75}$ ) was used within the human PBPK models to compute the hepatic clearance.

The rate of metabolism was calculated on the basis of hepatic clearance (i.e., hepatic clearance times the arterial concentration) $[4,40,41,45]$. For chloroethane, dichloromethane, vinyl chloride, and dibromomethane a first-order constant $\left(1,2,1\right.$, and $0.7 \mathrm{~h}^{-1}$, resp.) was included in the calculation of the hepatic clearance, $C L_{h}(\mathrm{~L} / \mathrm{h})[41]$ :

$$
C L_{h}=Q_{L} \cdot E,
$$

where $E=\left(C L_{\text {int }}+K_{f} \cdot V_{L}\right) /\left(\left(C L_{\text {int }}+K_{f} \cdot V_{L}\right)+Q_{L}\right), \mathrm{Q}_{\mathrm{L}}$ is the blood flow through the liver $(\mathrm{L} / \mathrm{h}), C L_{\text {int }}$ the intrinsic clearance (L blood/h), $K_{f}$ the first order metabolic constant $\left(\mathrm{h}^{-1}\right)$, and $\mathrm{V}_{L}$ the liver volume $(\mathrm{L})$.

2.3. $P B P K$ Modeling. The $\mathrm{QPPR}$ values of $C L_{\mathrm{int}}$ were included in a human PBPK model for inhaled VOCs [50]. Briefly, the PBPK model consisted in four tissue compartments (i.e., liver, fat, richly, and poorly perfused tissues) and a gas exchange lung, which were interconnected by blood flows. The distribution of VOCs into tissue compartments was described as perfusion limited, and the metabolism was limited to liver.

To evaluate the impact of uncertainty on the metabolic rate, for all the chemicals, $\mathrm{PBPK}$ simulations were also conducted by setting the value of $E$ to $0.999\left(E_{\max }\right)$ and then to $0.001\left(E_{\min }\right)$, respectively.

The human physiological parameters of the PBPK model (i.e., body weight $=70 \mathrm{~kg}$; cardiac output $=18 \mathrm{~L} / \mathrm{h} / \mathrm{kg}^{0.74}$; alveolar ventilation $=18 \mathrm{~L} / \mathrm{h} / \mathrm{kg}^{0.74}$; tissue compartment volumes, fraction of body weight:liver $=0.026$; richly perfused tissues $=0.05$; poorly perfused tissues $=0.62$; fat $=0.19$; perfusion of the tissue compartments, fraction of cardiac output:liver $=0.26$; richly perfused tissues $=0.44$; poorly perfused tissues $=0.25$; fat $=0.05$ ) were obtained from Tardif et al. [67]. Table 1 presents the value of the partition coefficients used in the PBPK model (i.e., blood:air, tissue:blood, and phospholipid: blood PCs). The phospholipid: blood PC was calculated using (1), whereas the blood: air PC and tissue: blood PCs were gathered from the literature $[48,50$, 52, 54, 56-59, 61, 66, 67, 77-80].

The PBPK model (differential and algebraic massbalance equations, physiological parameters, QSPR equations for metabolic constants, and PCs) was written in ACSL (acslX, version 2.5, Aegis Technologies Group, Inc, Huntsville, AL). The model code is included in the supplementary data available online at doi:10.1155/2012/286079. To compare the impact of different (uncertain) scenarios of rate of metabolism on the pharmacokinetics in human, simulations were carried out by setting (i) the value of $C L_{\text {int }}$ equal to the lower and upper bound of the QPPR predicted mean 95\% confidence interval, or (ii) the liver extraction ratio to 0.001 (no metabolism) and 0.999 (maximum extraction). The $24 \mathrm{~h}$ venous blood kinetics corresponding to the four scenarios of metabolism were simulated for an $8 \mathrm{~h}$ exposure to $1 \mathrm{ppm}$ of each VOC. The $24 \mathrm{~h}$ area under the curve $\left(\mathrm{AUC}_{24}\right)$ of the venous blood kinetics was also calculated to compare the four scenarios of metabolism simulated with PBPK models. Additionally, the venous blood kinetics of $m$-xylene, toluene, ethylbenzene, dichloromethane, styrene, 1,2,4-trimethylbenzene, and 1,1,1-trichloroethane were compared to experimental data $[61,67,81-83]$.

2.4. Analysis of Applicability of the $C L_{\mathrm{int}} \mathrm{QPPR}$ to PBPK Modeling. The applicability of the QPPR model was evaluated on the basis of the level of uncertainty in the QPPR estimate and the impact (sensitivity) of metabolism on the $\mathrm{AUC}_{24}$. Figure 1 illustrates the role of uncertainty and sensitivity in the reliability of the QPPR-PBPK modeling framework, based on reference [84]. The sensitivity of the metabolism to the AUC was estimated by the ratio of the $\mathrm{AUC}_{24}$ obtained with no metabolism $\left(E_{\min }\right)$ to that obtained with the maximum theoretical metabolism $\left(E_{\max }\right)$. The sensitivity of $\mathrm{AUC}_{24}$ to metabolism was considered to be low, medium, or high if the ratio $\left(A U C_{E_{\min }} / A_{U C} E_{E_{\max }}\right)$ was within a factor of 2 , within an order of magnitude, or greater. The uncertainty in the QPPR prediction was evaluated by comparing it 


\begin{tabular}{|c|c|c|c|c|}
\hline \multirow{2}{*}{\multicolumn{2}{|c|}{$\begin{array}{l}\text { Confidence } \\
\text { in the QPPR- } \\
\text { PBPK model }\end{array}$}} & \multicolumn{3}{|c|}{$\begin{array}{l}\text { Impact of metabolism on AUC } \\
\left(A U C_{E_{\min }} / \mathrm{AUC}_{E_{\max }}\right)\end{array}$} \\
\hline & & Low & Medium & High \\
\hline \multirow{3}{*}{ 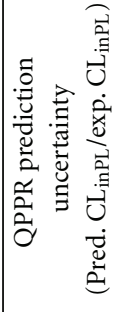 } & $\begin{array}{l}\text { Low } \\
(<2)\end{array}$ & High & High & High \\
\hline & $\begin{array}{l}\text { Medium } \\
(2-10)\end{array}$ & High & Medium & Medium \\
\hline & $\begin{array}{l}\text { High } \\
(>10)\end{array}$ & High & Medium & Low \\
\hline
\end{tabular}

FIGURE 1: Evaluation of the confidence in applying the QPPR for $C L_{\text {intPL }}$ in a PBPK model using a sensitivity/uncertainty approach.

to the experimental data. The prediction uncertainty was considered to be low, medium or high if the prediction was within a factor of two, within an order of magnitude and above 10 -fold of the experimental data, respectively.

This approach was applied to evaluate the reliability of applying the QPPR within the PBPK model for two situations: (i) for the calibration set of chemicals, for which the uncertainty of the QPPR was evaluated by comparing the predictions of $C L_{\text {intPL }}$ with the experimentally derived $C L_{\text {intPL }}$ values and (ii) for chemicals in the evaluation dataset, for which the uncertainty in the QPPR prediction was considered to be "high", to replicate the "data poor" situations with new or tested chemicals with unknown experimental $C L_{\text {int }}$ values.

\section{Results}

3.1. QPPR Development. The initial effort to develop a QPPR model for metabolism rate (expressed as $C L_{\text {intblood }}$, in units of $\mathrm{L}$ blood/hr), based on a stepwise analysis of its relationship to various molecular descriptors and physicochemical properties, was not successful (not shown). Same analysis, repeated for $C L_{\text {int }}$ expressed in units of $\mathrm{L} \mathrm{PL} / \mathrm{h}\left(C L_{\mathrm{intPL}}\right)$, yielded a QPPR that consisted of $\log P_{\mathrm{plw}}, \log P_{\mathrm{bw}}$, and IP (ionization potential, $\mathrm{eV}$ ) as input parameters. This model satisfied the criteria for an acceptable model in terms of coefficient of determination $\left(R^{2}=0.802 ; R_{\mathrm{adj}}^{2}=0.775\right)$, leave-one-out cross validation $\left(Q^{2}=0.755\right)$, and multicollinearity (VIFs: $\left.\log P_{\text {plw }}=2.42 ; \log P_{\mathrm{bw}}=2.38 ; \mathrm{IP}=1.04\right)$. The values of the regression coefficients were significant $(P$ value $<0.001$ for the constant, $\log P_{\mathrm{plw}}$ and $\log P_{\mathrm{bw}}$, and 0.007 for IP).

However, as the value of $\log P_{\text {ow }}$ can be obtained more readily than $\log P_{\mathrm{plw}}$, the regression analysis was repeated by using $\log P_{\mathrm{ow}}, \log P_{\mathrm{bw}}$, and calculated IP, and it yielded the following QPPR:

$$
\begin{aligned}
\log C L_{\mathrm{intPL}}= & 5.63( \pm 1.187)-1.287( \pm 0.149) \cdot \log P_{\mathrm{ow}} \\
& +1.08( \pm 0.233) \cdot \log P_{\mathrm{bw}} \\
& -0.328( \pm 0.111) \cdot \mathrm{IP} .
\end{aligned}
$$

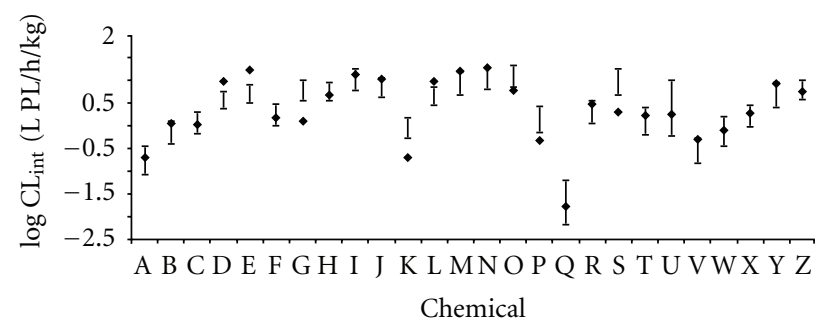

Figure 2: Experimental and predicted values of $\log C L_{\text {int }}$ for 26 VOCs. The horizontal bars represent the QPPR predicted LMCI and UMCI, the symbols represent the experimental data. A: 1,1,1,2-tetrachloroethane; B: 1,1,2,2-tetrachloroethane; C: 1,1,2trichloroethane; D: 1,1-dichloroethane; E: 1,1-dichloroethylene; F: 1,2-dichloroethane; G: 1,2-dichloroethylene (cis-); H: benzene; I: bromochloromethane; J: bromodichloromethane; K: carbon tetrachloride; L: chloroethane; M: chloroform; N: dibromomethane; O: dichloromethane; P: ethylbenzene; Q: hexachloroethane; R: isoprene; S: methyl chloride; T: $m$-xylene; $\mathrm{U}: n$-hexane; V: pentachloroethane; W: styrene; X: toluene; Y: trichloroethylene; Z: vinyl chloride.

This QPPR model satisfied the criteria for an acceptable model in terms of coefficient of determination $\left(R^{2}=\right.$ $\left.0.796 ; R_{\text {adj }}^{2}=0.768\right)$, leave-one-out cross validation $\left(Q^{2}=0.748\right)$, and multicollinearity (VIFs: $\log P_{\text {ow }}=2.42$; $\left.\log P_{\mathrm{bw}}=2.38 ; \mathrm{IP}=1.04\right)$. The application domain of the model can be described with [min; $\max ]$ as follows: $\log P_{\text {ow }}=[1.09 ; 4.03] ; \log P_{\text {bw }}[0.16 ; 2.49]$; calculated ionization potential [9.13;11.28].

The QPPR (5) was subsequently applied to calculate the $C L_{\text {intPL }}$ of the VOCs in the calibration set. Table 2 presents the values of the input parameters, along with the experimental data for the 26 VOCs used in QPPR development. Figure 2 illustrates the comparison of the predicted values of $C L_{\text {intPL }}$ (LMCI and UMCI) and the experimental data. The uncertainty in the predicted log $C L_{\text {intPL }}$ can be characterized by the difference between the $\mathrm{UMCI}$ and the LMCI; this value ranged from $0.37(1,1-$ dichloroethane) to 1.23 ( $n$-hexane) with a mean of 0.54 and a standard deviation of 0.18 . The nearest confidence bounds of the predicted $\log C L_{\text {intPL }}$ were higher than 5-fold of the experimental value (exp.) for three substances (cis1,2-dichloroethylene, $\mathrm{LMCI}=0.55$ versus exp. $=0.09$; styrene, $\mathrm{LMCI}=-0.45$ versus exp. $=-0.09$; and $1,1,2-$ trichloroethane, $\mathrm{UMCI}=0.46$ versus exp. $=0.02)$. The impact of the imprecision of these QPPR predictions of the metabolic constants on the pharmacokinetics in humans was then evaluated by PBPK modeling.

Figure 3 presents the predictions of the $24 \mathrm{~h}$ blood pharmacokinetics following $8 \mathrm{~h}$ exposure to $1 \mathrm{ppm}$ of each of the 26 VOCs used in the QPPR analysis. The bold lines represent the simulations obtained using 0 and 1 as the hepatic extraction ratio, whereas the grey area encompassed by thin lines represents the simulation obtained using LMCI and UMCI of predicted $C L_{\text {int }}$ in PBPK models. Overall, the envelope of the concentrations predicted using the QPPR predictions reduced the region of uncertainty associated with 
TABLE 2: Input parameters and experimental data of $\log C L_{\text {int } P L}$.

\begin{tabular}{|c|c|c|c|c|c|}
\hline \multirow{2}{*}{ Chemical } & \multicolumn{3}{|c|}{ Input parameters } & \multirow{2}{*}{$\log C l_{\text {intPL }}{ }^{a}\left(\mathrm{~L}_{P L} / \mathrm{h} / \mathrm{kg}\right)$} & \multirow{2}{*}{$\operatorname{Ref} V_{\max }, K_{n}$} \\
\hline & $\log P_{\text {ow }}$ & $\log P_{\mathrm{bw}}$ & Ionization potential $(\mathrm{eV})$ & & \\
\hline Benzene & 1.99 & 0.820 & 9.743 & 0.667 & {$[53]$} \\
\hline Bromochloromethane & 1.43 & 0.642 & 10.562 & 1.118 & [49] \\
\hline Bromodichloromethane & 1.61 & 0.717 & 10.676 & 1.029 & {$[46]$} \\
\hline Carbon tetrachloride & 2.44 & 0.988 & 10.985 & -0.700 & {$[24]$} \\
\hline Chloroethane & 1.58 & 0.438 & 10.410 & 0.987 & [24] \\
\hline Chloroform & 1.52 & 0.741 & 10.839 & 1.192 & {$[24]$} \\
\hline Dibromomethane & 1.52 & 0.777 & 10.587 & 1.275 & {$[51]$} \\
\hline Dichloroethane (1,1-) & 1.76 & 0.624 & 10.577 & 0.974 & [24] \\
\hline Dichloroethane $(1,2-)$ & 1.83 & 0.356 & 10.446 & 0.163 & {$[24]$} \\
\hline Dichloroethylene (1,1-) & 2.12 & 0.922 & 9.748 & 1.223 & {$[24]$} \\
\hline Dichloroethylene (cis-1,2) & 1.98 & 0.752 & 9.493 & 0.092 & [24] \\
\hline Dichloromethane & 1.34 & 0.608 & 10.582 & 0.777 & {$[24]$} \\
\hline Ethylbenzene & 3.03 & 1.386 & 9.406 & -0.334 & [49] \\
\hline Hexachloroethane & 4.03 & 1.315 & 10.843 & -1.767 & {$[24]$} \\
\hline Hexane $(n-)$ & 3.29 & 2.492 & 11.276 & 0.252 & [47] \\
\hline Isoprene & 2.58 & 0.987 & 9.349 & 0.472 & {$[52]$} \\
\hline Methyl chloride & 1.09 & 0.160 & 10.473 & 0.299 & {$[24]$} \\
\hline Pentachloroethane & 3.11 & 1.251 & 10.763 & -0.297 & {$[24]$} \\
\hline Styrene & 2.89 & 0.889 & 9.130 & -0.088 & [50] \\
\hline Tetrachloroethane $(1,1,1,2-)$ & 2.93 & 0.836 & 10.728 & -0.693 & {$[24]$} \\
\hline Tetrachloroethane $(1,1,2,2-)$ & 2.19 & 0.519 & 10.736 & 0.051 & {$[24]$} \\
\hline Toluene & 2.54 & 0.879 & 9.442 & 0.282 & [49] \\
\hline Trichloroethane $(1,1,2-)$ & 2.01 & 0.491 & 10.689 & 0.018 & {$[24]$} \\
\hline Trichloroethylene & 2.47 & 1.192 & 9.368 & 0.916 & {$[24]$} \\
\hline Vinyl chloride & 1.62 & 0.433 & 9.833 & 0.741 & {$[24]$} \\
\hline Xylene $(m-)$ & 3.09 & 1.388 & 9.308 & 0.218 & [48] \\
\hline
\end{tabular}

${ }^{a}$ : EXP. experimental data (references in Section 2); LMCI and UMCI: lower and upper bound of the $95 \%$ mean confidence interval, respectively.

the complete lack of knowledge of hepatic extraction ratio in humans (i.e., ranging from 0 to 1 ).

The average ratio ( \pm standard deviation) of the PBPK model simulated values of the end-of-exposure blood concentrations (i.e., $C_{\max }$ ) obtained with $E_{\min }$ and $E_{\max }$ was $4.19 \pm 1.81$. The lowest and highest ratios, based on the theoretical bounds of hepatic extraction (i.e., $E_{\min }$ and $\left.E_{\max }\right)$, were observed for isoprene (1.63) and 1,1,2,2tetrachloroethane (8.05), respectively. However, the average ratio ( \pm standard deviation) of the PBPK model simulated values of the end-of-exposure blood concentrations, based on QPPR-generated bounds (LMCI, UMCI), was $1.29 \pm$ 0.27 . This ratio was the highest for hexachloroethane (2.39) and the lowest for 1,1-dichloroethylene (1.06).

For the 26 VOCs used in the development of the QPPR, the values of $\mathrm{AUC}_{24} \mathrm{~s}$ for a $1 \mathrm{ppm}$ continuous exposure are reported in Table 3. The ratio of the highest to the lowest AUC predicted with $E_{\min }$ and $E_{\max }$ was $4.3 \pm 1.94$ ranging from 1.63 (isoprene) to 8.7 (1,1,2,2-tetrachloroethane). The ratio of the maximum to minimum concentrations predicted using the QPPR metabolism rate was $1.36 \pm 0.4$ ranging from 1.06 (1,1-dichloroethylene) to 2.8 (isoprene).
Figure 4 illustrates the range of predictions of venous blood pharmacokinetics compared to experimental data $[67,81,82]$. Overall, the predicted envelope of concentrations approximated reasonably the experimental data for dichloromethane, ethylbenzene, styrene, toluene, and $m$ xylene.

3.2. Analysis of Applicability of the $C L_{\text {int }} Q P P R$ to $P B P K$ Modeling. The reliability of applying the QPPR within the PBPK model was assessed for the 26 VOCs in the calibration dataset (Table 4). The uncertainty of the QPPR prediction was estimated as the ratio of predicted $C L_{\text {intPL }}$ to experimental $C L_{\text {intPL }}$. For 3 VOCs (isoprene, 1,1-dichloroethylene, and vinyl chloride) the sensitivity of AUC to $C L_{\text {int }}$ was low (ratio of AUCs $<2$ ) whereas uncertainty of the $C L_{\text {int }}$ QPPR was low for isoprene and vinyl chloride and medium for 1,1dichloroethylene. For the other 23 VOCs, the ratio of AUCs was between 2 and 5. For 16 of the later 23 VOCs (benzene; bromochloromethane; bromodichloromethane; chloroform; dibromomethane; 1,2-dichloroethane; hexachloroethane; $n$-hexane; pentachloroethane; styrene; 


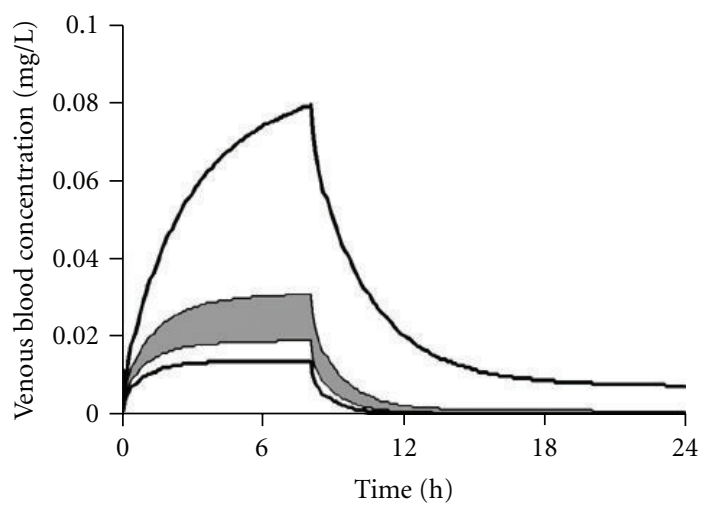

(a)

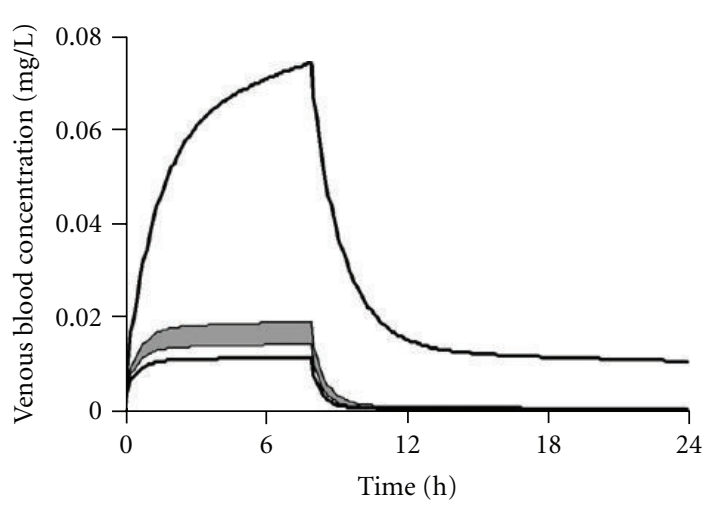

(c)

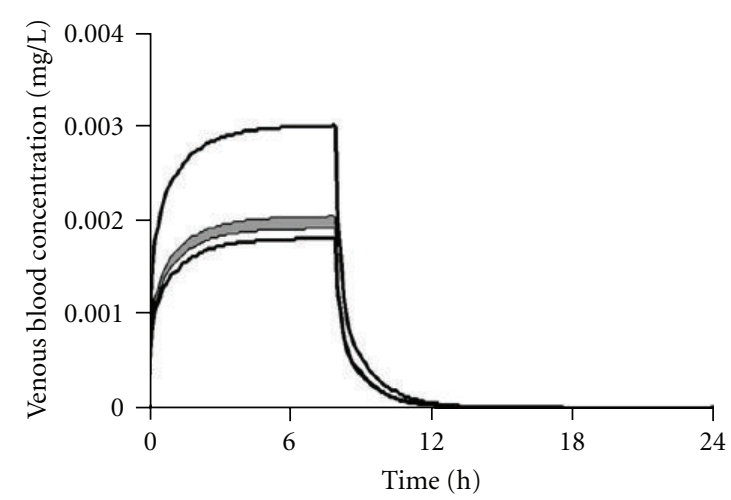

(e)

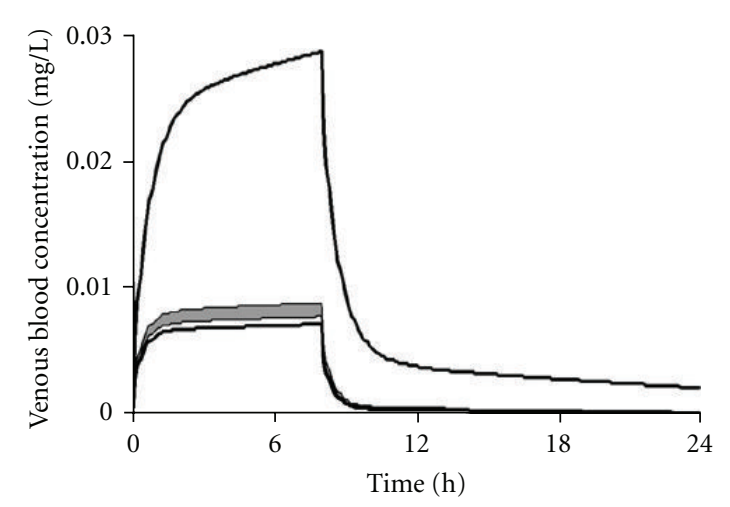

(g)

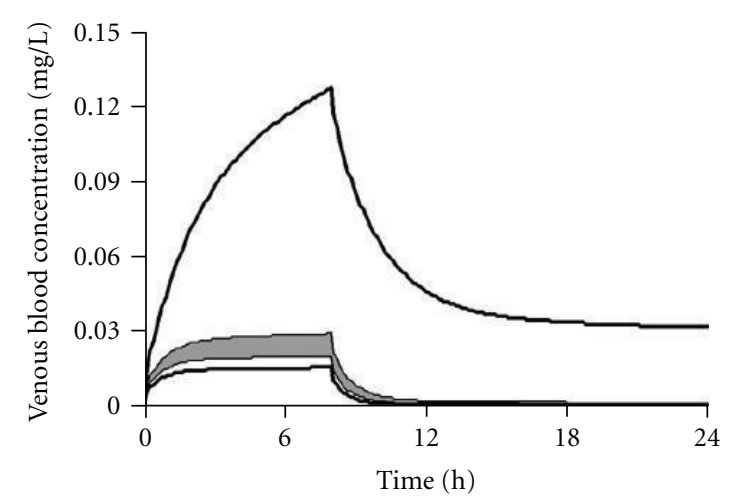

(b)

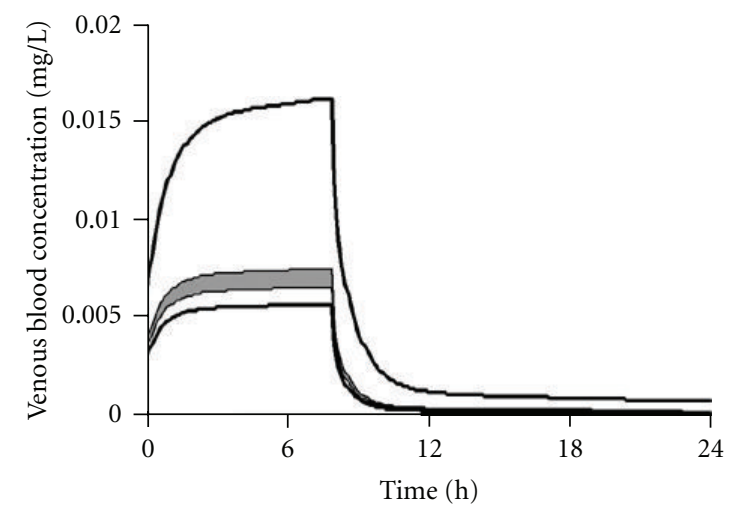

(d)

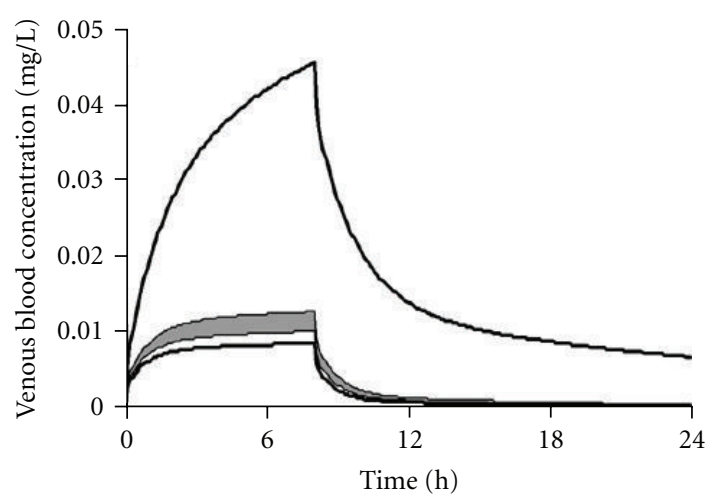

(f)

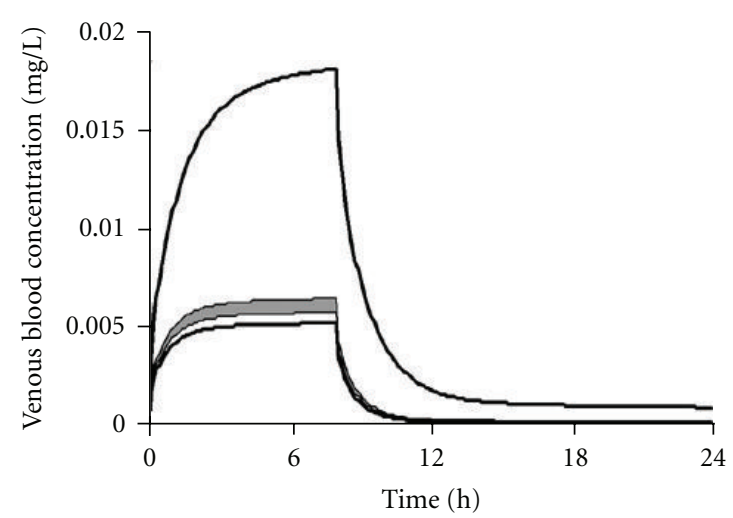

(h)

Figure 3: Continued. 


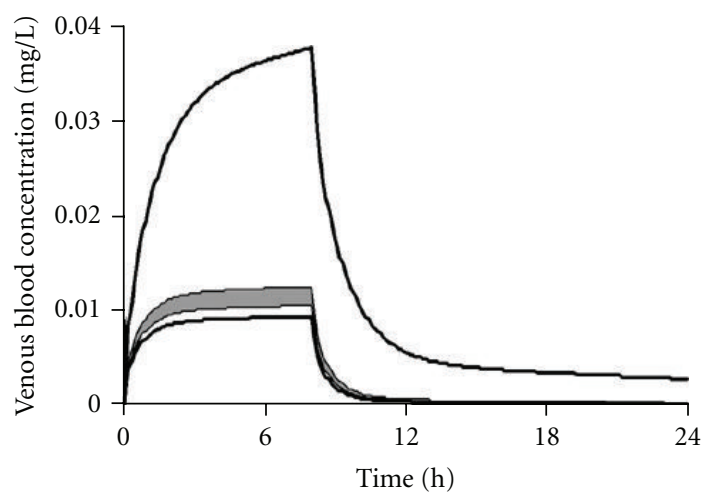

(i)

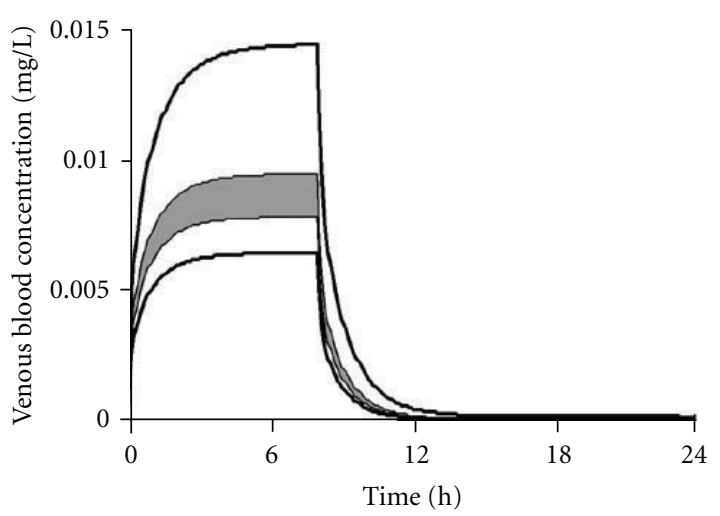

(k)

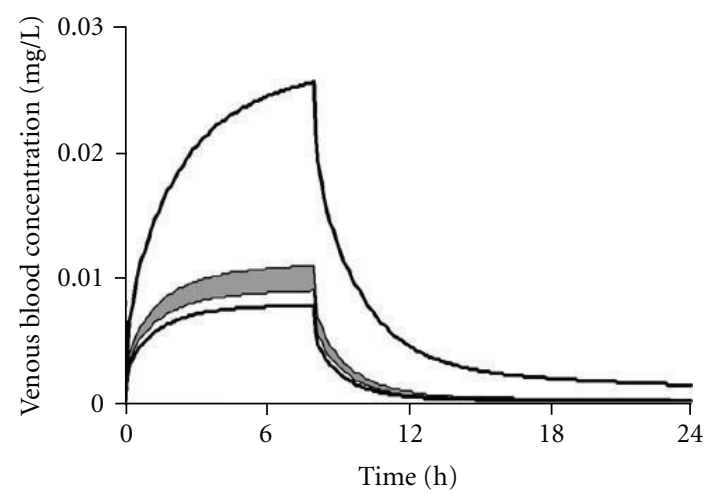

(m)

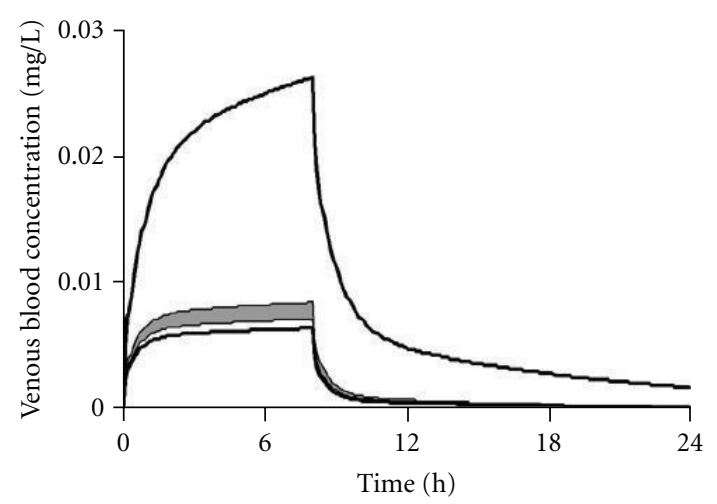

(o)

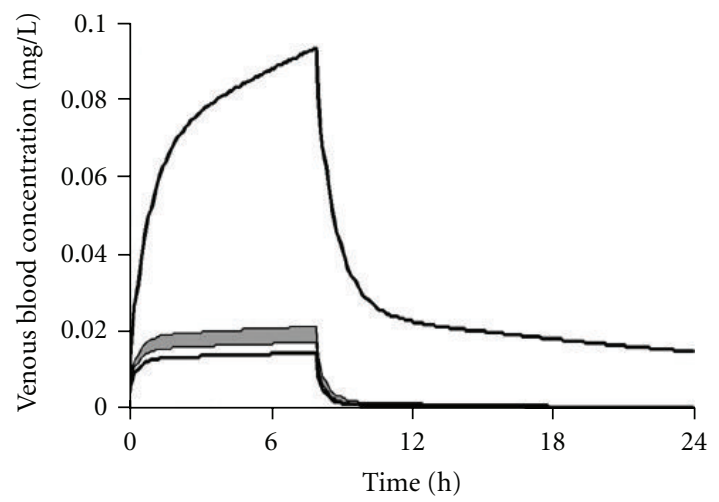

(j)

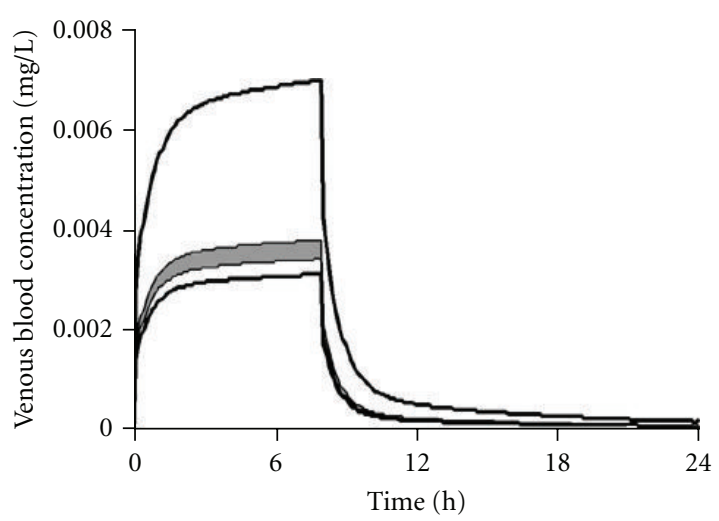

(1)

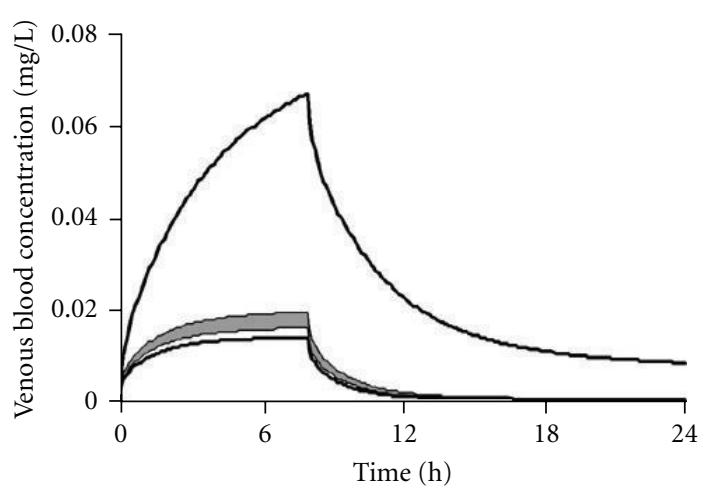

(n)

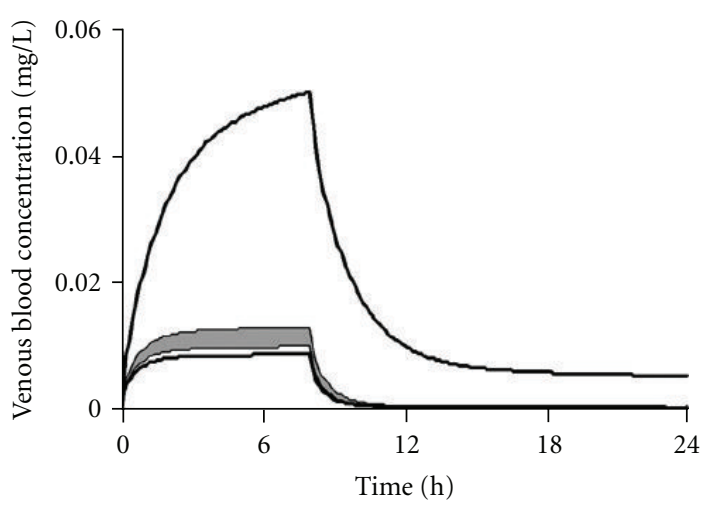

(p)

FIgure 3: Continued. 


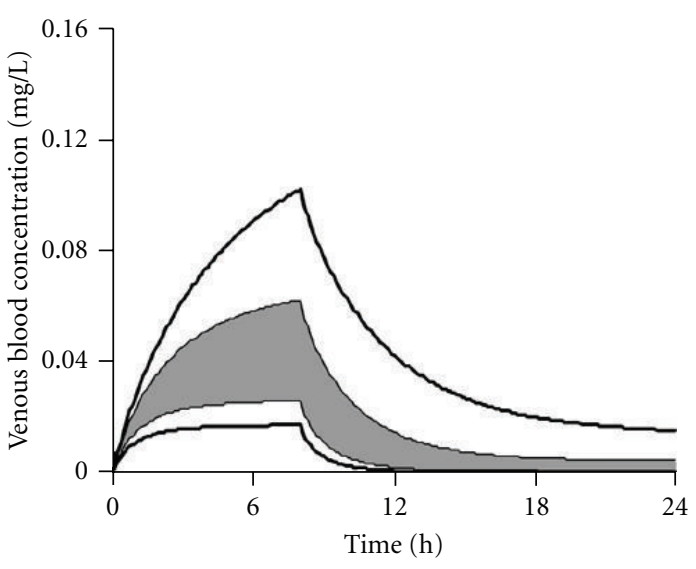

(q)

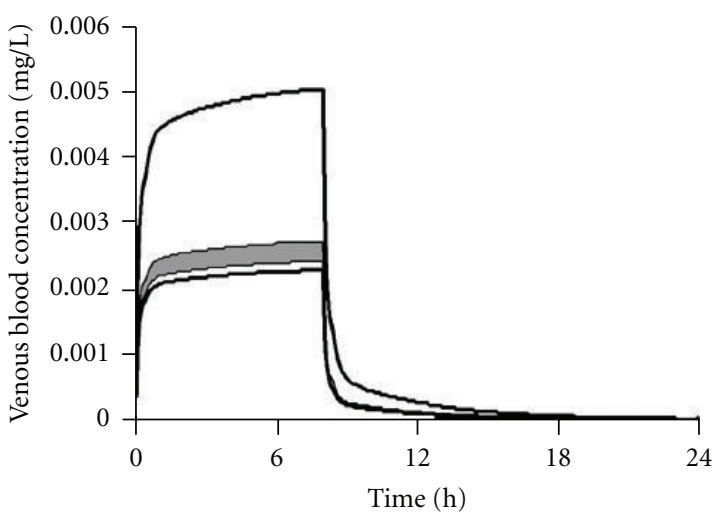

(s)

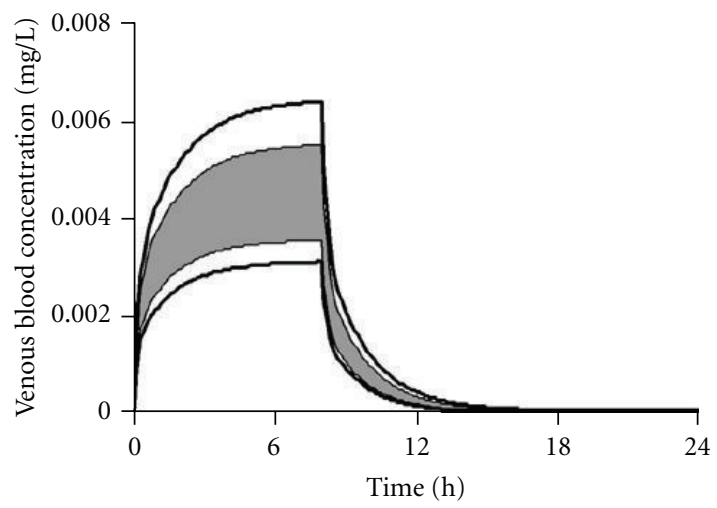

(u)

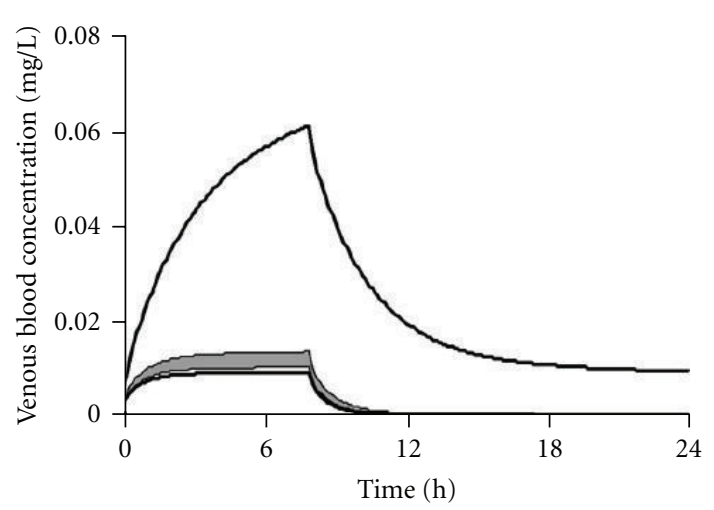

(w)

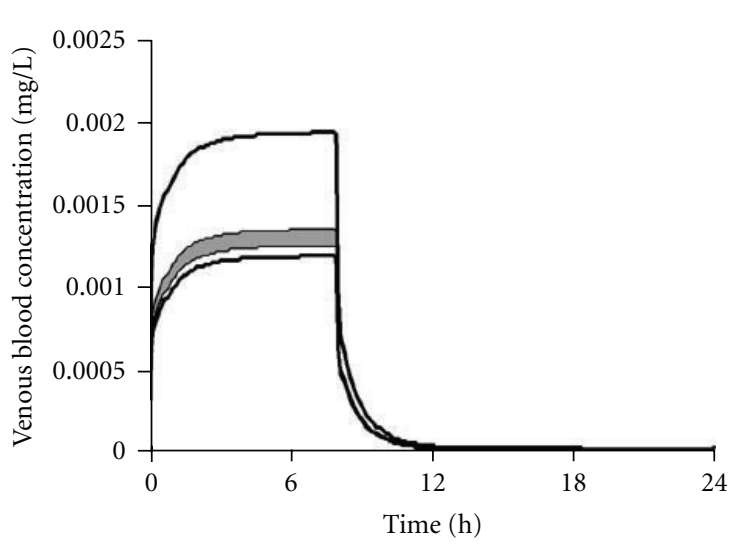

(r)

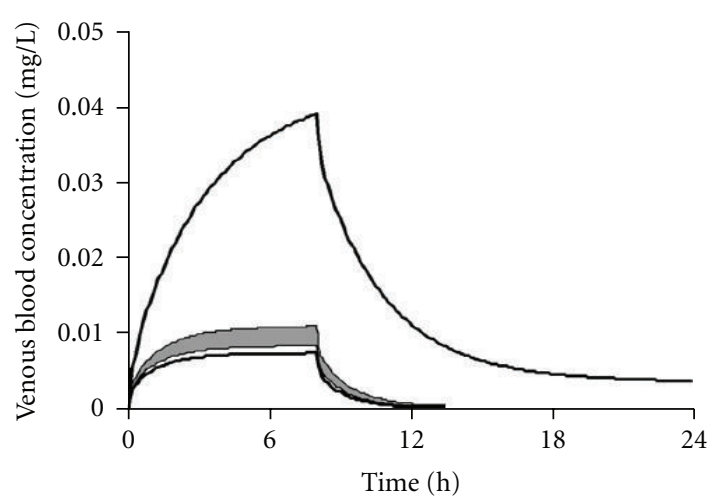

(t)

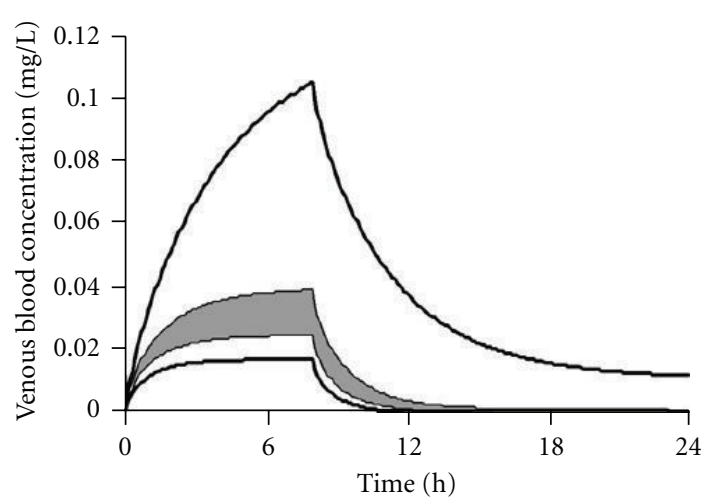

(v)

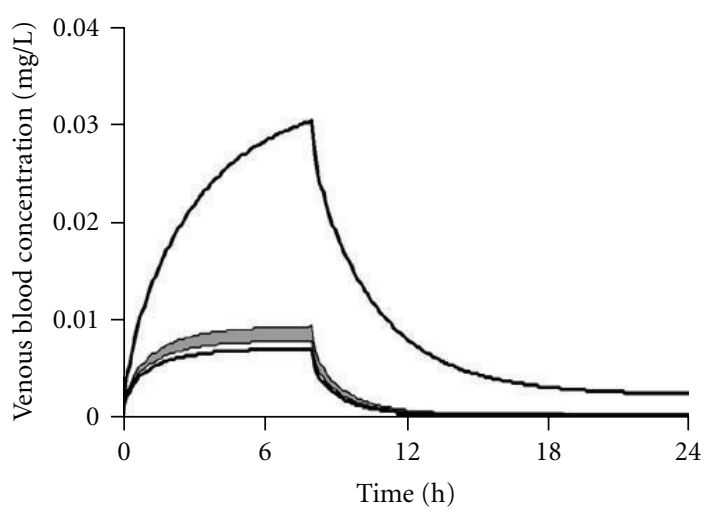

(x)

Figure 3: Continued. 


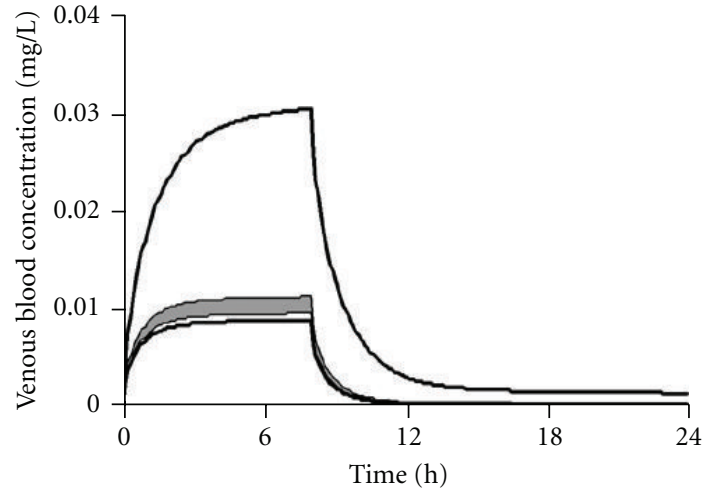

(y)

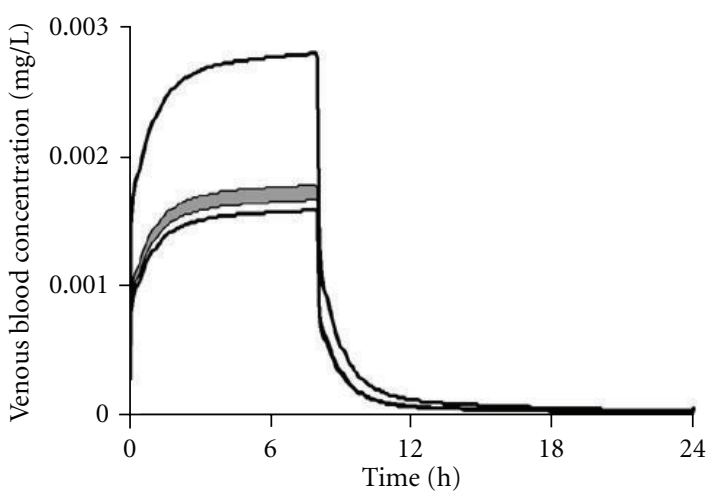

(z)

FIGURE 3: $24 \mathrm{~h}$ simulation of the venous blood concentration following inhalation exposure to $1 \mathrm{ppm}, 8 \mathrm{~h}$ for 26 volatile organic compounds considering maximum and minimum (bold lines) and QPPR-based hepatic extraction (grey area). (a) 1,1,1,2-Tetrachloroethane; (b) 1,1,2,2-tetrachloroethane; (c) 1,1,2-trichloroethane; (d) 1,1-dichloroethane; (e) 1,1-dichloroethylene; (f) 1,2-dichloroethane; (g) 1,2dichloroethylene (cis-); (h) benzene; (i) bromochloromethane; (j) bromodichloromethane; (k) carbon tetrachloride; (l) chloroethane; (m) chloroform; ( $\mathrm{n}$ ) dibromomethane; (o) dichloromethane; (p) ethylbenzene; (q) hexachloroethane; (r) isoprene; (s) methyl chloride; (t) $m$ xylene; (u) $n$-hexane; (v) pentachloroethane; (w) styrene; (x) toluene; (y) trichloroethylene; (z) vinyl chloride.

TABLe 3: Area under the curve for four metabolic scenarios for the VOCs used in the QPPR development.

\begin{tabular}{|c|c|c|c|c|}
\hline \multirow{3}{*}{ Chemicals } & \multicolumn{4}{|c|}{$24 \mathrm{~h}$ Area under the curve (mg/L-h) } \\
\hline & \multicolumn{4}{|c|}{ Metabolic scenario $^{\mathrm{a}}$} \\
\hline & $E_{\min }$ & $E_{\max }$ & LMCI & UMCI \\
\hline Benzene & 0.437 & 0.125 & 0.155 & 0.138 \\
\hline Bromochloromethane & 0.913 & 0.229 & 0.305 & 0.257 \\
\hline Bromodichloromethane & 2.380 & 0.356 & 0.523 & 0.422 \\
\hline Carbon tetrachloride & 0.34 & 0.153 & 0.224 & 0.186 \\
\hline Chloroethane & 0.156 & 0.069 & 0.084 & 0.076 \\
\hline Chloroform & 0.599 & 0.185 & 0.257 & 0.211 \\
\hline Dibromomethane & 1.659 & 0.336 & 0.466 & 0.384 \\
\hline Dichloroethane $(1,1-)$ & 0.391 & 0.138 & 0.181 & 0.158 \\
\hline Dichloroethane $(1,2-)$ & 1.142 & 0.205 & 0.305 & 0.241 \\
\hline Dichloroethylene (1,1-) & $6.98 \times 10^{-2}$ & $4.22 \times 10^{-2}$ & $4.76 \times 10^{-2}$ & $4.47 \times 10^{-2}$ \\
\hline Dichloroethylene (cis-1,2) & 0.702 & 0.174 & 0.214 & 0.188 \\
\hline Dichloromethane & 0.65 & 0.157 & 0.206 & 0.174 \\
\hline Ethylbenzene & 1.247 & 0.216 & 0.32 & 0.246 \\
\hline Hexachloroethane & 3.071 & 0.494 & 1.774 & 0.738 \\
\hline Hexane $(n-)$ & 0.15 & 0.073 & 0.129 & 0.084 \\
\hline Isoprene & $4.59 \times 10^{-2}$ & $2.81 \times 10^{-2}$ & 0.084 & $2.95 \times 10^{-2}$ \\
\hline Methyl chloride & 0.119 & 0.054 & 0.064 & 0.057 \\
\hline Pentachloroethane & 2.584 & 0.418 & 0.929 & 0.595 \\
\hline Styrene & 1.497 & 0.222 & 0.322 & 0.246 \\
\hline Tetrachloroethane $(1,1,1,2-)$ & 1.911 & 0.337 & 0.739 & 0.457 \\
\hline Tetrachloroethane $(1,1,2,2-)$ & 3.337 & 0.384 & 0.717 & 0.495 \\
\hline Toluene & 0.74 & 0.168 & 0.223 & 0.188 \\
\hline Trichloroethane $(1,1,2-)$ & 1.876 & 0.284 & 0.474 & 0.355 \\
\hline Trichloroethylene & 0.721 & 0.209 & 0.267 & 0.227 \\
\hline Vinyl chloride & $6.68 \times 10^{-2}$ & $3.79 \times 10^{-2}$ & $4.25 \times 10^{-2}$ & $3.98 \times 10^{-2}$ \\
\hline Xylene $(m-)$ & 1.117 & 0.209 & 0.308 & 0.236 \\
\hline
\end{tabular}

\footnotetext{
${ }^{a}: E_{\min }$ : no metabolism; $E_{\max }$ : maximum hepatic extraction; LMCI and UMCI: lower and upper bound of the $95 \%$ mean confidence interval, respectively.
} 


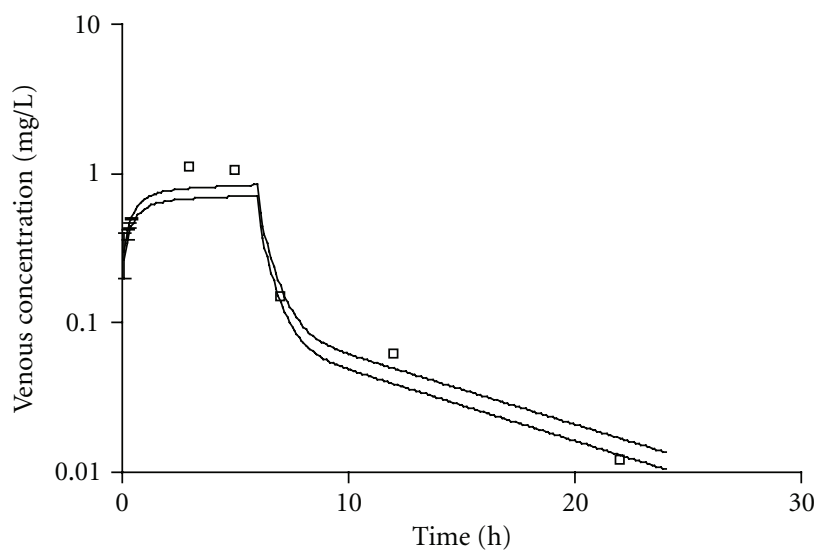

(a)

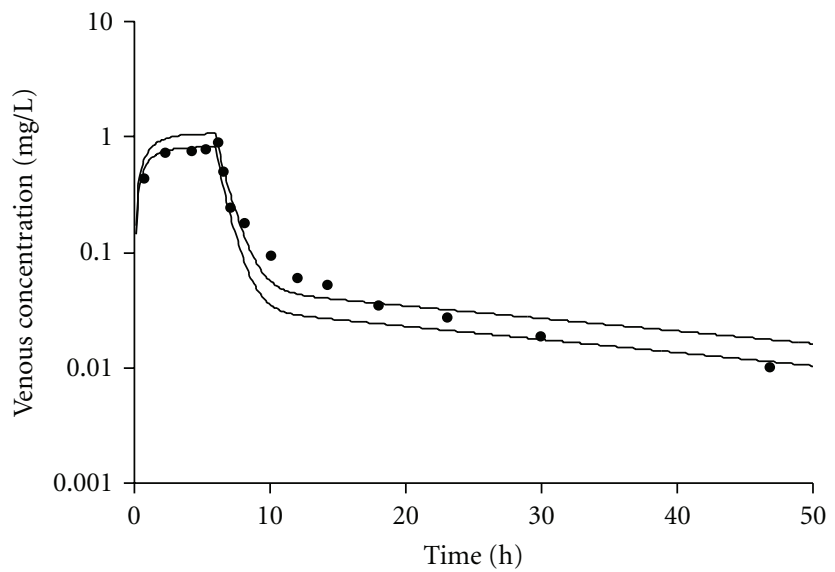

(c)

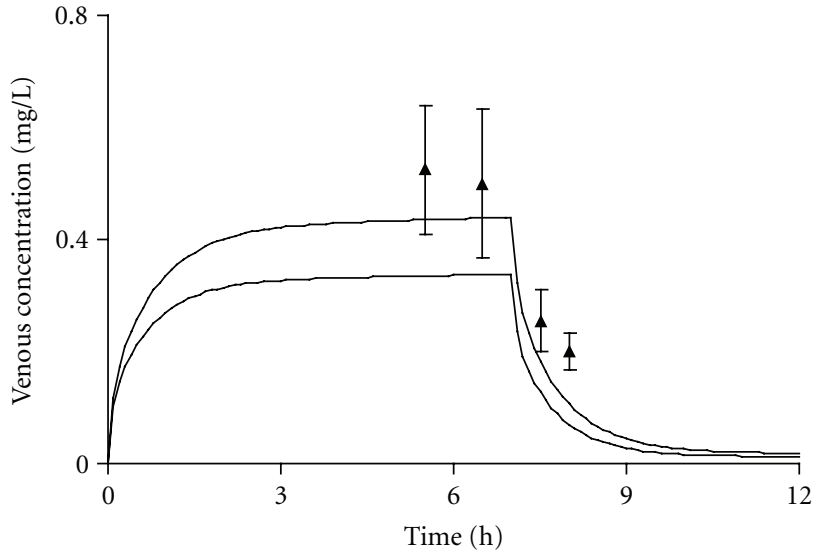

(b)

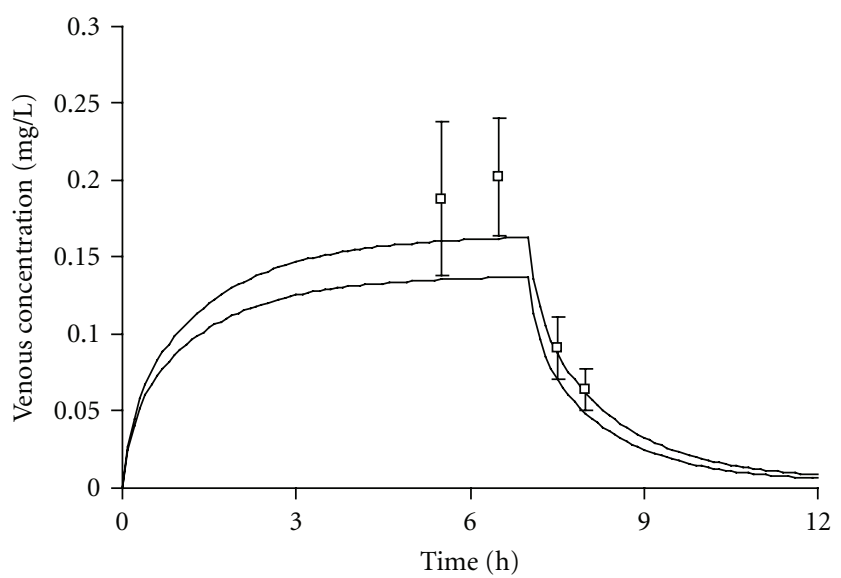

(d)

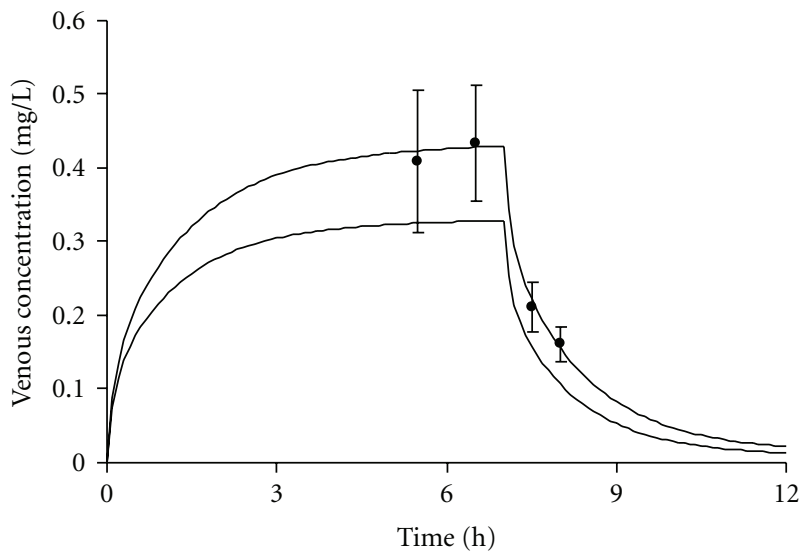

(e)

FIgURE 4: Comparison of PBPK model simulation with experimental data of venous blood concentration following inhalation exposure to (a) $100 \mathrm{ppm}, 6 \mathrm{~h}$ dichloromethane [77]; (b) $33 \mathrm{ppm}, 7 \mathrm{~h}$ ethylbenzene [67]; (c) $80 \mathrm{ppm}, 6 \mathrm{~h}$ styrene [78]; (d) $17 \mathrm{ppm}, 7 \mathrm{~h}$ toluene [67]; (e) $33 \mathrm{ppm}, 7 \mathrm{~h} m$-xylene [67]. Bold lines: predicted LMCI and UMCI for $C L_{\text {int }}$.

1,1,1,2-tetrachloroethane; 1,1,2,2-tetrachloroethane; toluene; 1,1,2-trichloroethane; trichloroethylene; $m$-xylene) the prediction uncertainty was low, thus the confidence in using the QPPR in the PBPK model is high for these compounds. The uncertainty was medium for the prediction of $C L_{\text {intPL }}$ for 7 VOCs (carbon tetrachloride; chloroethane; 1,1-dichloroethane; cis-1,2-dichloroethylene; dichloromethane; ethylbenzene; methyl chloride). Therefore, for these chemicals, the confidence in using the QPPR in an inhalation PBPK model to evaluate the AUC is medium. 
TABLE 4: Reliability analysis of the QPPR for $C L_{\text {int }}$ on the PBPK predicted AUC.

\begin{tabular}{|c|c|c|c|c|}
\hline & & Impact & metabolism on $\mathrm{AUC}\left(\mathrm{AUC}_{E_{\min }} / \mathrm{AUC}_{E_{\max }}\right)^{\mathrm{a}}$ & \\
\hline & & Low $(<2)$ & Medium (2-5) & High $(>5)$ \\
\hline $\begin{array}{l}\text { QPPR prediction } \\
\text { uncertainty (Pred./Exp. } \\
\left.\mathrm{CL}_{\text {intPL }}\right)^{\mathrm{b}}\end{array}$ & Low $(<2)$ & Isoprene, vinyl chloride & $\begin{array}{l}\text { Benzene; bromochloromethane; } \\
\text { bromodichloromethane; chloroform; } \\
\text { dibromomethane; } 1,2 \text {-dichloroethane; } \\
\text { hexachloroethane; } n \text {-hexane; } \\
\text { pentachloroethane; styrene; } \\
\text { 1,1,1,2-tetrachloroethane; } \\
\text { 1,1,2,2-tetrachloroethane; toluene; } \\
\text { 1,1,2-trichloroethane; trichloroethylene; } \\
m \text {-xylene }\end{array}$ & \\
\hline & Medium (2-5) & 1,1,-Dichloroethylene & $\begin{array}{l}\text { Carbon tetrachloride; chloroethane; } \\
\text { 1,1-dichloroethane; } \\
\text { cis-1,2-dichloroethylene; dichloromethane; } \\
\text { ethylbenzene; methyl chloride }\end{array}$ & \\
\hline
\end{tabular}

${ }^{a}$ Calculated as the ratio of the PBPK simulations of $24 \mathrm{~h}$ AUC (of venous blood concentration, $1 \mathrm{ppm}$ VOC, $24 \mathrm{~h}$ exposure) obtained by setting $E=0$ (i.e., $C L_{\text {int }}=0$ ) to that setting $E=1$ (i.e., $C L_{\text {int }}=1000$ ).

$\mathrm{b}$ Calculated as the ratio of the predicted to the experimental values of $C L_{\text {intPL. }}$.

TABLE 5: Input parameters and experimental data on $\log C L_{\text {int }}$ for VOCs of QPPR evaluation.

\begin{tabular}{|c|c|c|c|c|c|}
\hline \multirow{2}{*}{ Chemical } & \multicolumn{3}{|c|}{ Input parameters } & \multirow{2}{*}{$\log C l_{\text {intPL }}{ }^{a}\left(\mathrm{~L}_{\mathrm{PL}} / \mathrm{h} / \mathrm{kg}\right)$} & \multirow{2}{*}{$\operatorname{Ref} V_{\max }, K_{m}$} \\
\hline & $\log P_{\text {ow }}$ & $\log P_{\mathrm{bw}}$ & $\mathrm{IP}(\mathrm{eV})$ & & \\
\hline Bromoform & 1.79 & 0.896 & 10.837 & 1.006 & {$[46]$} \\
\hline Dibromochloromethane & 1.70 & 1.025 & 10.702 & 1.108 & {$[46]$} \\
\hline Dichloroethylene (trans-1,2-) & 1.98 & 0.484 & 9.512 & 0.438 & {$[55]$} \\
\hline Ethylene & 1.27 & 0.776 & 10.638 & 1.208 & {$[59]$} \\
\hline Furan & 1.36 & 0.441 & 9.375 & 1.773 & {$[56]$} \\
\hline Halothane & 2.26 & 0.977 & 11.039 & 1.104 & {$[58]$} \\
\hline Propylene & 1.68 & 0.995 & 10.103 & 1.118 & {$[54]$} \\
\hline Tetrachloroethylene & 2.97 & 1.404 & 9.217 & -1.804 & {$[57]$} \\
\hline Trichloroethane $(1,1,1-)$ & 2.68 & 0.823 & 10.751 & -2.467 & {$[48]$} \\
\hline Trimethylbenzene $(1,2,4-)$ & 3.63 & 1.829 & 9.084 & -0.132 & {$[61]$} \\
\hline Xylene $(o-)$ & 3.09 & 1.213 & 9.304 & 0.163 & {$[60]$} \\
\hline
\end{tabular}

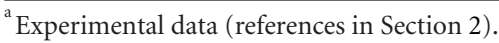

3.3. QPPR Evaluation. The QPPR model was applied to predict the $C L_{\text {intPL }}$ of 11 VOCs that were not in the calibration dataset. Table 5 presents the values of the input parameters along with the experimental data for the 11 VOCs used in QPPR evaluation. Figure 5 illustrates the comparison of the predicted values of $C L_{\text {intPL }}$ (LMCI and $\mathrm{UMCI})$ and the experimental data. The average difference $( \pm$ standard deviation) between the UMCI and the LMCI was $0.57 \pm 0.11$ ranging from 0.46 (bromoform) to $0.84(1,2,4$ trimethylbenzene). The highest UMCI-LMCI ranges were obtained for furan (0.62), tetrachloroethylene (0.63), and 1,2,4-trimethylbenzene (0.84). The nearest predicted values of UMCI and LMCI on $\log C L_{\text {intPL }}$ were greater than 5 -fold of the experimental data for tetrachloroethylene $(\mathrm{LMCI}=0.02$ versus $\exp =-1.8)$. As in the QPPR development section, the impact of the imprecision on these $\log C L_{\text {int }}$ predictions on the pharmacokinetics in humans was evaluated by PBPK modeling.

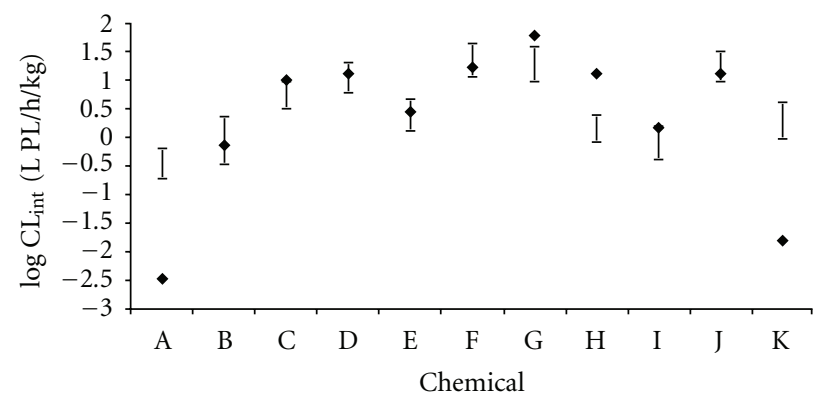

Figure 5: Comparison of the predicted log $C L_{\text {int }}$ (LMCI and UMCI) with the experimental data on 11 VOCs. The bars represent the QPPR predictions and the symbols the experimental values. A: 1,1,1-trichloroethane; B: 1,2,4-trimethylbenzene; C: 1,2-dichloroethylene (trans-); D: bromoform; E: dibromochloromethane; F: ethylene; G: furan; H: halothane; I: $o$-xylene; J: propylene; K: tetrachloroethylene. 


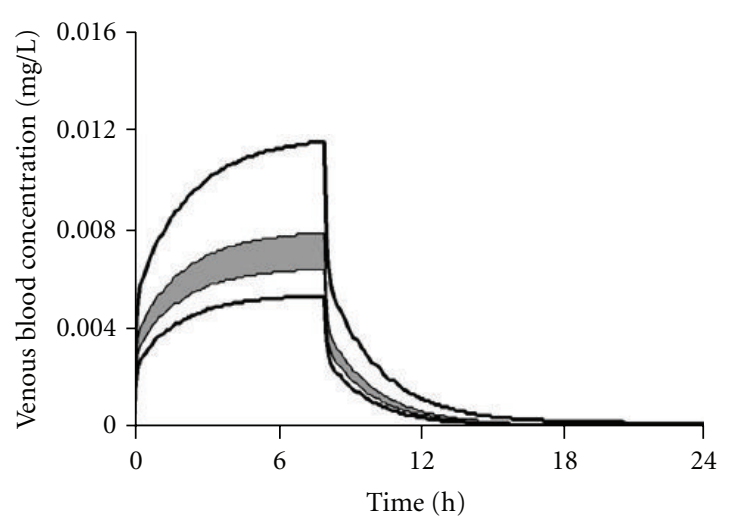

(a)

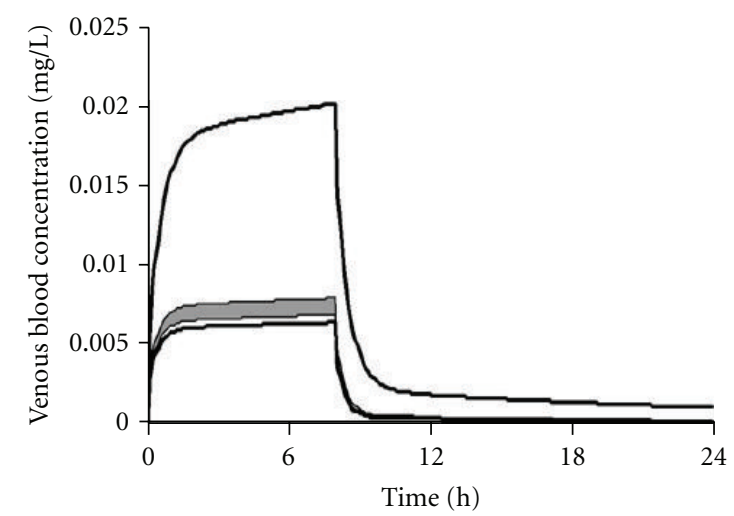

(c)

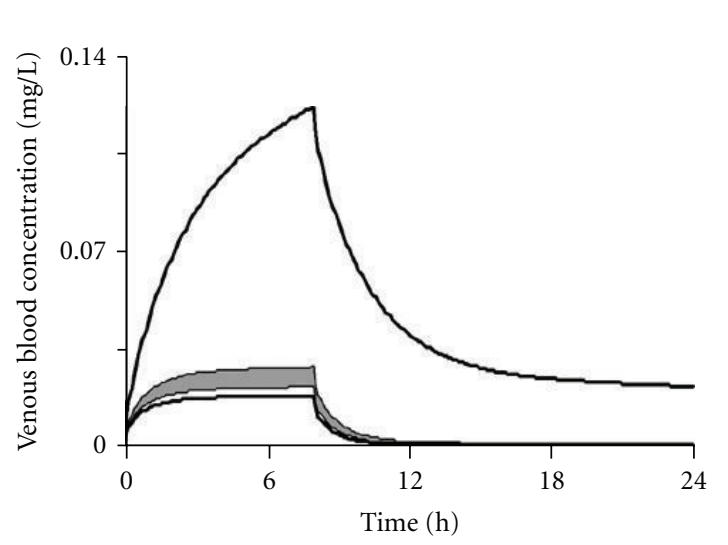

(e)

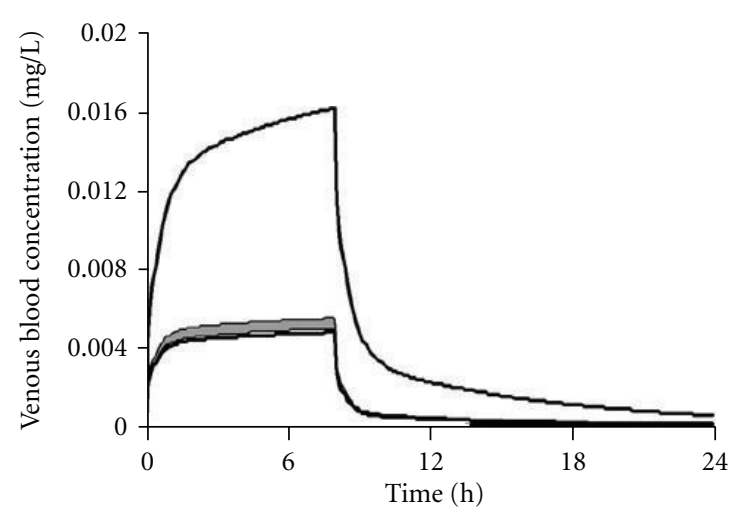

(g)

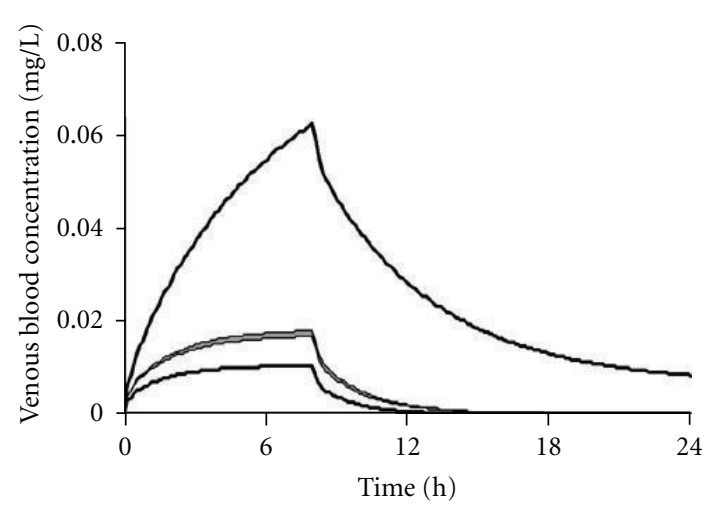

(b)

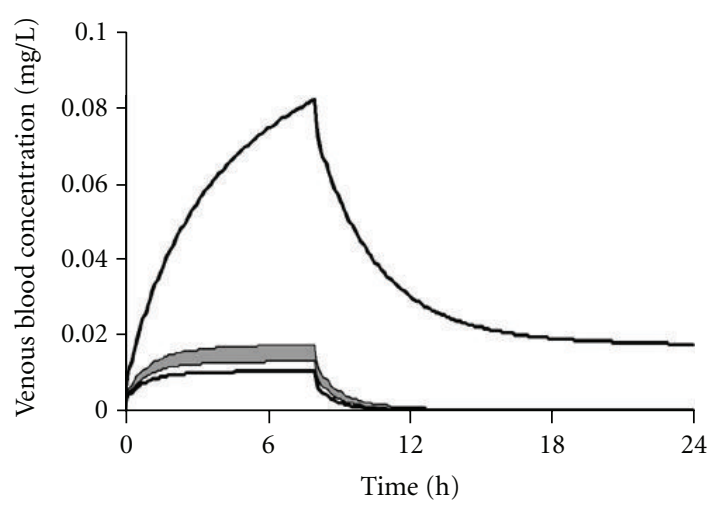

(d)

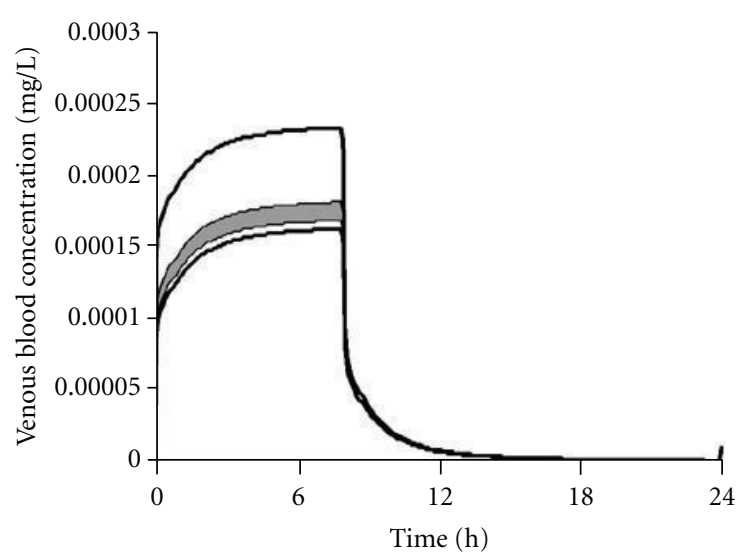

(f)

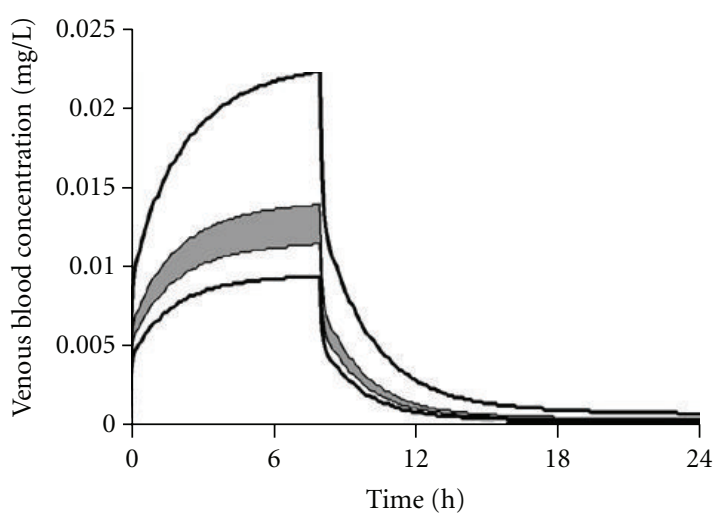

(h)

FIGURE 6: Continued. 


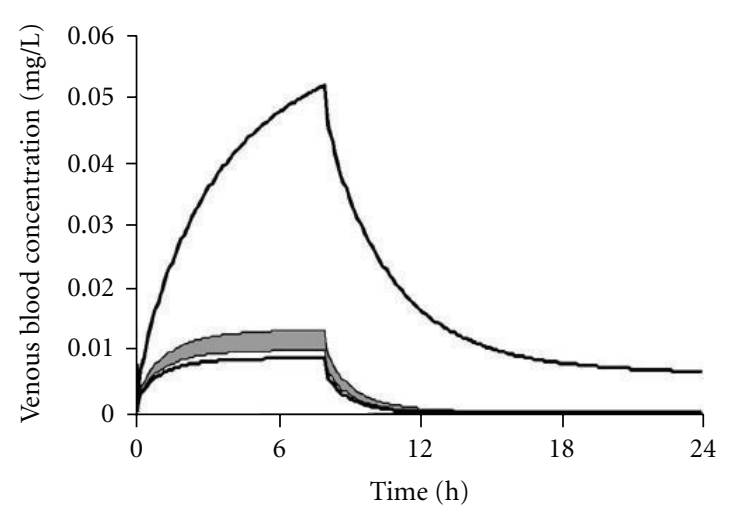

(i)

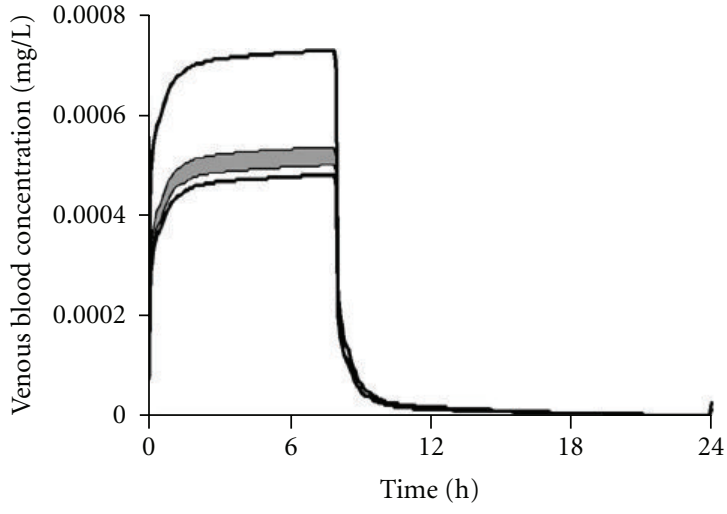

(j)

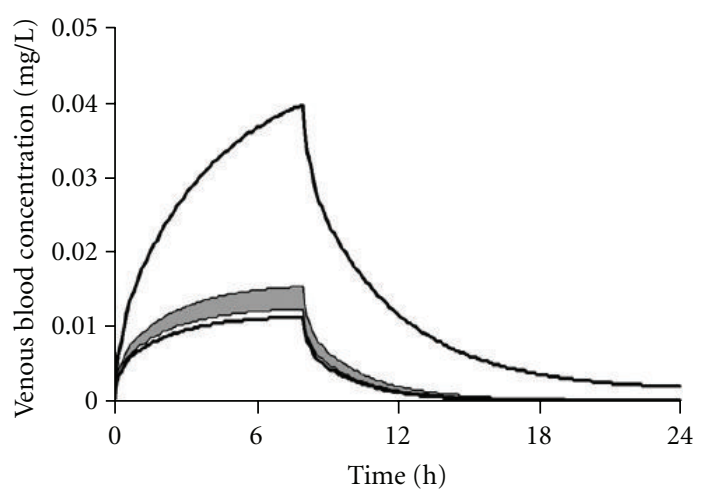

(k)

Figure 6: $24 \mathrm{~h}$ simulation of the venous blood concentration following inhalation exposure to $1 \mathrm{ppm}, 8 \mathrm{~h}$ for 11 volatile organic compounds considering maximum and minimum (bold lines) and QPPR-based hepatic extraction (grey area). (a) 1,1,1-Trichloroethane; (b) 1,2,4trimethylbenzene; (c) 1,2-dichloroethylene (trans-); (d) bromoform; (e) dibromochloromethane; (f) ethylene; (g) furan; (h) halothane; (i) $o$-xylene; (j) propylene; (k) tetrachloroethylene.

Figure 6 presents the predictions of the $24 \mathrm{~h}$ blood pharmacokinetics following $8 \mathrm{~h}$ exposure to $1 \mathrm{ppm}$ of each of the 11 VOCs used in the QPPR evaluation. The bold lines represent the simulations obtained using 0 and 1 as the hepatic extraction ratio, whereas the grey area encompassed by thin lines represents the simulation obtained using LMCI and UMCI of predicted $C L_{\text {int }}$ in PBPK models. The reduction of the region of uncertainty associated with the complete lack of knowledge of hepatic extraction ratio in humans (i.e., ranging from 0 to 1 ) by the envelope of the concentrations predicted using the QPPR predictions was observed for the 11 VOCs.

The mean ratio ( \pm standard deviation) of the PBPK model simulated values of the end-of-exposure blood concentrations obtained with $E_{\min }$ and $E_{\max }$ was $3.92 \pm 2.13$ ranging from 1.42 (ethylene) to 7.45 (bromoform). However, the same average ratio ( \pm standard deviation) of PBPK simulated blood concentrations, based on QPPR-generated bounds (LMCI and UMCI) was $1.2 \pm 0.1$, ranging from 1.07 (ethylene) to 1.33 (bromoform).

Table 6 presents the values of the $\mathrm{AUC}_{24} \mathrm{~s}(\mathrm{mg} / \mathrm{L}-\mathrm{h})$ for the 11 VOCs used in the evaluation of the QPPR. The average ratio of the highest to lowest AUC predicted using $E_{\min }$ and $E_{\max }$ was $4.08 \pm 2.31$ (mean $\left.\pm \mathrm{SD}\right)$. The lowest and highest ratios, based on the theoretical bounds of hepatic extraction (i.e., $E=0.001$ or 0.999 ), were observed for ethylene (1.44) and bromoform (7.96), respectively.

The ratio of the maximum to minimum concentrations predicted using the QPPR metabolism rate was 1.2 \pm 0.1 , ranging from 1.07 (propylene) to 1.33 (dibromochloromethane).

Figure 7 illustrates the range of predictions for two of the chemicals in the external dataset (1,2,4-trimethylbenzene and 1,1,1-trichloroethane) venous blood pharmacokinetics compared to experimental data $[61,85]$. The QPPR-PBPK model-generated "envelope" of concentrations simulated reasonably the experimental data for 1,2,4-trimethylbenzene whereas the blood concentrations of 1,1,1-trichloroethane were underestimated by about $30 \%$.

3.4. Analysis of Applicability of the $C L_{\text {int }} Q P P R$ to $P B P K$ Modeling. The reliability of applying the QPPR within the PBPK model was assessed for the 11 VOCs in the evaluation dataset, using the framework shown in Figure 1. Considering that the experimental data of $C L_{\text {intPL }}$ for new or untested chemicals will be essentially unknown, it is realistic to consider the uncertainty of the QPPR prediction of $C L_{\text {intPL }}$ to be high for all chemicals in the evaluation dataset. 
TABLE 6: Area under the curve for four metabolic scenarios, for VOCs in the evaluation dataset.

\begin{tabular}{|c|c|c|c|c|}
\hline \multirow{3}{*}{ Chemicals } & \multicolumn{4}{|c|}{$24 \mathrm{~h}$ Area under the curve (mg/L-h) } \\
\hline & \multicolumn{4}{|c|}{ Metabolic scenario $^{\mathrm{a}}$} \\
\hline & $E_{\min }$ & $E_{\max }$ & LMCI & UMCI \\
\hline Bromoform & 2.122 & 0.267 & 0.434 & 0.328 \\
\hline Dibromochloromethane & 3.114 & 0.45 & 0.7 & 0.527 \\
\hline Dichloroethylene (trans-1,2-) & 0.472 & 0.149 & 0.185 & 0.16 \\
\hline Ethylene & $5.87 \times 10^{-3}$ & $4.08 \times 10^{-3}$ & $4.55 \times 10^{-3}$ & $4.23 \times 10^{-3}$ \\
\hline Furan & 0.388 & 0.113 & 0.131 & 0.118 \\
\hline Halothane & 0.523 & 0.22 & 0.325 & 0.266 \\
\hline Propylene & $1.76 \times 10^{-2}$ & $1.16 \times 10^{-2}$ & $1.3 \times 10^{-2}$ & $1.21 \times 10^{-2}$ \\
\hline Tetrachloroethylene & 0.953 & 0.266 & 0.363 & 0.291 \\
\hline Trichloroethane $(1,1,1-)$ & 0.271 & 0.125 & 0.184 & 0.15 \\
\hline Trimethylbenzene $(1,2,4-)$ & 1.577 & 0.249 & 0.425 & 0.395 \\
\hline Xylene $(o-)$ & 1.297 & 0.218 & 0.325 & 0.248 \\
\hline
\end{tabular}

${ }^{\mathrm{a}}: E_{\min }$ : no metabolism; $E_{\max }$ : maximum hepatic extraction; LMCI and UMCI: lower and upper bound of the $95 \%$ mean confidence interval, respectively.

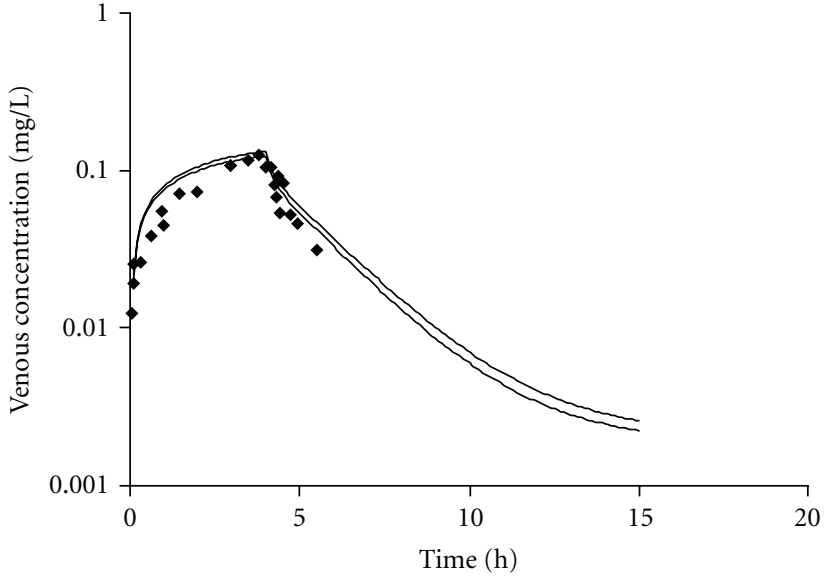

(a)

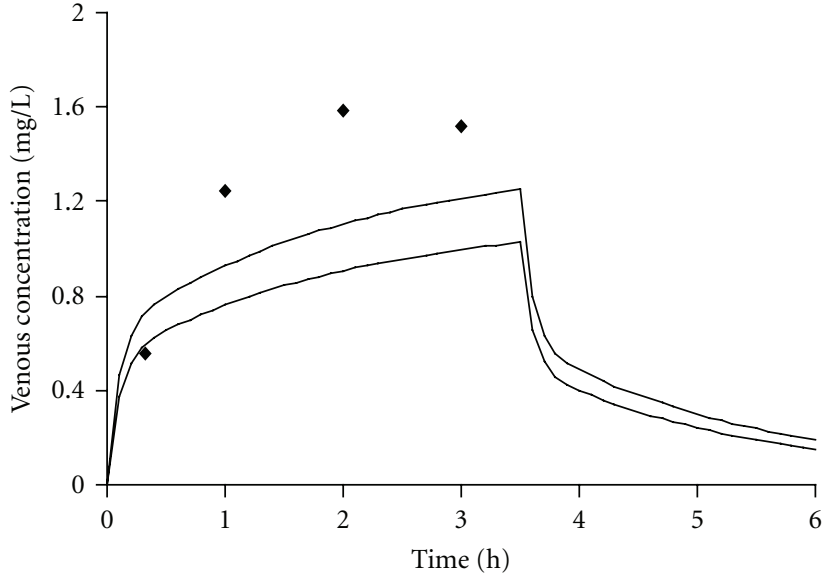

(b)

FIGURE 7: Comparison of PBPK model simulations (bold lines: predicted LMCI and UMCI for $C L_{\text {int }}$ ) with experimental data of venous blood concentration following inhalation exposure to (a) 8 ppm, $4 \mathrm{~h} \mathrm{1,2,4-trimethylbenzene} \mathrm{[59]} \mathrm{and} \mathrm{(b)} \mathrm{175} \mathrm{ppm,} \mathrm{3.5} \mathrm{h} \mathrm{1,1,1-trichloro}$ ethane [85].

The results of the analysis of applicability for the chemicals in the evaluation dataset are reported in Table 7. For 3 VOCs (ethylene; propylene; 1,1,1-trichloroethane) the sensitivity was low (ratio of AUCs $<2$ ) thus the reliability of using their $C L_{\text {int }}$ QPPR in the PBPK was considered high. For the other 8 VOCs (bromoform; dibromochloromethane; trans1,2-dichloroethylene; furan; halothane; tetrachloroethylene; 1,2,4-trimethylbenzene; $o$-xylene), the ratio of the maximum to the minimum possible AUCs was between 2 and 5, such that the confidence in using the QPPR in an inhalation PBPK model to evaluate the AUCs is medium for these chemicals.

\section{Discussion}

SARs, QSAR, QSPRs, and QPPRs have been developed for various toxicological and chemical properties but only very few studies have focused on developing such models to parameterize PBPK models $[8,86]$. A limitation in developing PBPK models relates to the availability of the metabolic constants $\left(C L_{\text {int }}, V_{\max }\right.$, and $\left.K_{m}\right)$ [8]. Quantitative relationships between structure and metabolism rates have been investigated for a limited number of closely related compounds, even though their applicability to PBPK modeling has not been demonstrated (e.g., QSPR models for $K_{\text {cat }}$ and $1 / K_{m}$ [87]). Other works in this area relate to the development of quantum chemical or quantum dynamic methods for prediction of activation energy or enthalpy of activation of P450 mediated reactions $[20,25,26,31,36$, $38,88-91$ ], which have not been used to derive metabolism constants for direct incorporation within rodent or human PBPK models.

The use of the group contribution method to develop QSPRs for integration within PBPK models has been successfully demonstrated, particularly for the inhalation toxicokinetics of VOCs [40-43]. This approach however is limited to VOCs containing one or more of the molecular groups 
TABLE 7: Reliability analysis for the chemicals in the QPPR evaluation dataset.

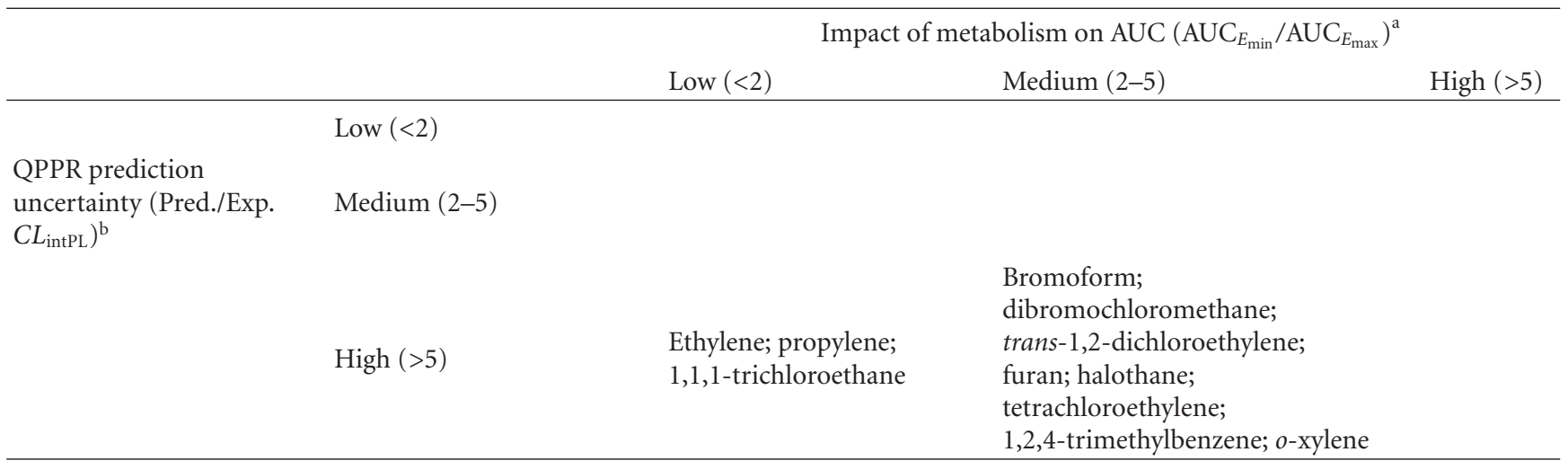

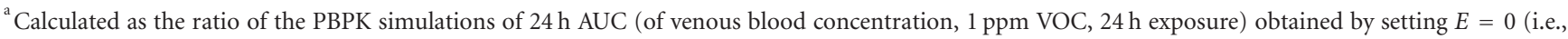
$C L_{\text {int }}=0$ ) to that setting $E=1$ (i.e., $C L_{\text {int }}=1000$ ).

${ }^{\mathrm{b}}$ Calculated as the ratio of the predicted to the experimental values of $C L_{\mathrm{int}} \mathrm{PL}$.
}

or fragments for which the contribution has been evaluated (i.e., $\mathrm{CH}_{3}, \mathrm{CH}_{2}, \mathrm{CH}, \mathrm{C}, \mathrm{C}=\mathrm{C}$, benzene ring, $\mathrm{H}$ on benzene ring, and halogens). In order to extend the applicability domain then, it is important to investigate the feasibility of developing QSPRs based on more global, physicochemical properties. In this regard, the present study investigated the development of a QPPR, that used chemical properties rather than chemical structure as input, and it was calibrated to predict $C L_{\text {int }}$ expressed in terms of chemical affinity to phospholipids in the endoplasmic reticulum in which CYP enzymes are embedded [63]. This logical transformation of $C L_{\text {int }}$ data, reported here for the first time in literature, facilitated the development of more adequate QPPR than the conventional $C L_{\text {int }}$ based on blood concentrations. All efforts to develop QPPRs for predicting $C L_{\text {int }}$ based on blood concentrations were unsuccessful. The QPPR based chemical affinity to phospholipids-obtained in this study should be regarded as a screening level tool to provide plausible range of metabolism rates in order to facilitate a first-cut evaluation of the blood concentration of inhaled VOCs in humans. The uncertainty associated with this QPPR tool should be evaluated along with the sensitivity of $C L_{\text {int }}$ on the dose metrics of the chemical of interest, in the perspective of intended precision. Accordingly, if the dose metric is highly sensitive to $C L_{\text {int }}$ and the QPPR predictions of $C L_{\text {int }}$ are highly uncertain, then the present tool is of limited use even for screening purposes. In such cases, then in vivo or in vitro studies can be undertaken to get chemical-specific estimates of $C L_{\text {int }}$.

The QPPR predictions were reasonably in accordance with experimental values for most but not all chemicals in the calibration and evaluation datasets. For some chemicals, the predicted values of $\log C L_{\text {int }}$ for 1,1,1-trichloroethane (Figure 5(A)) and tetrachloroethylene (Figure 5(K)) exceeded the experimental values by two orders of magnitude. The QSPR for rat hepatic clearance developed by Béliveau and colleagues [41] also overestimated the metabolic rate of these two VOCs. However the PBPK model for 1,1,1trichlorethane indicated that the AUC of parent chemical in venous blood is not sensitive to $V_{\max }$ and $K_{m}[92,93]$. This was demonstrated in Figure 6(a), showing that QPPRoverestimation of $C L_{\text {intPL }}$ of 1,1,1-trichloroethane led only to a minimal impact, in terms of the underestimation of the venous blood concentration. In the case of tetrachloroethylene, a poorly metabolized halogenated VOC, the overestimation of the $C L_{\text {intPL }}$ led to a 3-fold underestimation of the $C_{\max }$ (Figure 6(k)) or a 4-5-fold underestimation of the $\mathrm{AUC}_{24}$ (Table 7). If this magnitude of error is not acceptable for screening-level evaluation, then the metabolic rate should be experimentally determined. The combined assessment of the uncertainty/sensitivity of metabolic constants in PBPK models would facilitate the determination of the applicability of the QPPR model, given the level of precision need for an application (Figure 1)

The QPPR developed in this study is a generic tool to provide initial estimates of $C L_{\text {int }}$ of VOCs metabolized by hepatic CYP. It does not take into account stereochemistry or other pathway-specific rates and processes, which may be important for some chemicals (e.g., predicted values of $C L_{\text {int }}$ are almost identical for 1,1-dichloroethylene and cis1,2-dichloroethylene but experimental values vary by $\log$ units of 1.06). Therefore, predictions of $C L_{\text {int }}$ based on generic considerations are likely to be inaccurate for specific chemicals but are of limited use in that the estimates (along with the bounds, representing the level of uncertainty) can be integrated with human physiology to provide a first-cut view of the plausible kinetic profiles.

The utility of the QPPR models depends, in part, on the ability to reproducibly calculate the descriptors [74]. Hence, in this study, the descriptors that could be easily calculated and interpreted were chosen and obtained using EPISUITE (for $\log P_{\text {ow }}$ and $P_{\text {wa }}$ ) and MMPro (for the ionization potential). However, the blood solubility parameter (i.e., blood: air PC) is additionally required and this can either be obtained experimentally in vitro or using other QSARs that account for protein (i.e., haemoglobin and plasma protein) binding in addition to solubility considerations. There are some algorithms and QSARs available in this regard, but 
further development is necessary to adequately account for the protein binding phenomena in human blood for various classes of chemicals [8].

The QPPR developed in this study computes $C L_{\text {intPL, }}$ which can then be converted to $C L_{\text {intblood }}$ for use in PBPK modeling. In an effort to evaluate whether the same input parameters can be used to relate to $C L_{\text {intblood }}$, additional analyses were performed. These yielded the following equation (significant terms only):

$$
\log C L_{\text {intblood }}=5.117-0.305 \cdot \log P_{\text {ow }}-0.324 \cdot \mathrm{IP} .
$$

Even though (5) and (6) give almost identical results (one for $C L_{\text {intPL }}$ and the other for $C L_{\text {intblood }}$ ) despite the differing $R^{2}$ values (0.796 versus 0.402$)$, it should be noted that (5) was obtained based on statistical analysis of calibration dataset (i.e., modeling) whereas (6) was derived simply by fitting $C L_{\text {intblood }}$ to the specific input parameters. Further rearrangements and simplifications of the QPPR, as well as the loss of accuracy associated with such attempts, were not performed in the current study.

The output of the QPPR developed in the present study is $\log C L_{\text {int }}$, which is useful for simulating pharmacokinetics in humans of chemicals at low levels of exposure. $C L_{\text {int }}$ is applicable to first-order situations (i.e., when blood levels in humans are much lower than the $K_{m}$ for metabolizing enzyme) and is derived by dividing the $V_{\max }$ (i.e., the enzyme turn-over) with $K_{m}$ (representing the affinity of the substrate for the enzyme). The input parameters of the QPPR, namely, $\log P_{\mathrm{ow}}$ and $\log P_{\mathrm{bw}}$, are estimates of the relative solubility in octanol, water, and blood. Then, an interpretation of the model for $C L_{\text {int }}$ could be that the binding to the P450 enzyme is a result of hydrophobic interactions [94] which, in turn, can be estimated with parameters reflective of the solubility in $n$-octanol and blood. The solubility in blood is the sum of the solubility in its components (water, phospholipids, neutral lipids, and proteins). Most of the studied VOCs are likely to bind to hemoglobin because of their lipophilicity $\left(\log P_{\text {ow }}\right.$ value above 1$)$ and low molecular volume [40]. The $P_{\mathrm{bw}}$, thus, is likely an indicator of the binding to proteins, whereas the $\log P_{\text {ow }}$ reflects more the affinity for biotic lipids in the metabolism microenvironment. Similar to $\log P_{\text {ow }}$, the ionization potential has already been correlated with metabolic rates, namely, the $V_{\max }$ and $V_{\max } / k_{m}$ [23], as this latter parameter could be correlated with the energy needed to break a covalent bond for the oxidation of the substrate.

The QSPR model for $C L_{\text {int }}$ developed in this study has a defined theoretical endpoint, is nonambiguous, has a defined domain of application, was analyzed using appropriate goodness-of-fit $\left(R^{2}\right)$ and robustness $\left(Q^{2}\right)$, and has an attempt of mechanistic interpretation. The in vivo dataset on 26 VOCs used for the QPPR calibration was chosen because it was previously collated and used in QSPR analyses [40, 41]. These values were taken mainly from the work of Gargas et al. [24]. The QSPR analysis was also attempted with the entire dataset of 37 VOCs (calibration + external dataset) but it did not improve the goodness-of-fit statistics (not shown).

The predicted bounds of the $95 \%$ confidence interval of intrinsic clearance were incorporated within a PBPK model to predict the blood toxicokinetics of VOCs. The simulations of blood kinetics were comparable to experimental data for 6 VOCs (toluene, $m$-xylene, ethylbenzene, styrene, dichloromethane,1,2,4-trimethylbenzene, and 1,1,1trichloroethane, Figures 4 and 7). The simulations obtained in the present study, using lower and upper confidence intervals on the mean predicted $C L_{\text {int }}$, reduced clearly the uncertainty bounds associated with the total lack of knowledge (i.e., $E$ ranging anywhere between 0 and 1). Furthermore, the present study incorporated the QPPR predictions of $C L_{\text {int }}$ along with physiological parameters, such that impact on in vivo kinetics could be simulated. In effect, in some cases where the uncertainty on $C L_{\text {int }}$ predictions was high, it did not translate into a proportionate error on the predictions of kinetics, due to the additional consideration of physiological constraints, and such observations are critical in data-poor situations for designing focused studies to generate chemical-specific data in vitro or in vivo.

The QPPR developed in this study approximated the experimental rat metabolic constants for the various lowmolecular-weight VOCs; and it was used along with the human physiology to generate initial or screening level values of $C L_{\text {int }}$ to construct human PBPK models that could be of potential use to interpret data such as measured biomarker levels or for designing kinetic studies to reduce database uncertainty. As shown with some VOCs (e.g., Figure 3: 1,1,1,2-tetrachloroethane, hexachloroethane, and $n$-hexane), the blood concentration profile is extremely influenced by $C L_{\text {int }}$, such that metabolism cannot be neglected in simulating or interpreting human exposure data. And in such cases, the ability to generate at least a range of plausible values of $C L_{\text {int }}$, as done in the present study, would facilitate first inhuman simulations of pharmacokinetics of parent chemicals. Integrating information on the impact of metabolism on dose metrics (i.e., AUC) along with prediction uncertainty of the QPPR facilitates the determination of the level of confidence in using this screening level tool. Depending upon the overall confidence in the QPPR application for predicting dose metrics (low, medium, and high) relative to the use purposes, decisions can be made as to the specific studies needed.

Overall, the QPPR developed in the present study allows to predict the $C L_{\text {int }}$ of VOCs on the basis of generic molecular descriptors rather than with fragment constants as done previously. The chemical concentration in phospholipids, for the first time, was found to be a dose metric amenable to QPPR analysis. The QPPR was then used to generate range of values of $C L_{\text {int }}$; the level of confidence in these estimates was assessed by considering the impact of $C L_{\text {int }}$ on the simulated dose metrics (i.e., AUC of parent chemical in venous blood). For other dose metrics and situations, a more robust QPPR needs to be developed, and such efforts can be based on the methodological developments accomplished in this study. The QPPR-based simulation of pharmacokinetics reduced the range of uncertainty for few substances relative to complete lack of knowledge of the $C L_{\text {int }}$, but it needs to be evaluated/refined with much larger dataset should this screening-level approach be adopted for providing more precise estimates of metabolism rates. Overall, the integrated 
QPPR-PBPK model developed in this study is a potentially useful tool for characterizing and reducing the uncertainty associated with the complete lack of knowledge of $C L_{\text {int }}$ in predicting human pharmacokinetics of inhaled VOCs.

\section{Acknowledgments}

Financial support by Agence Française de Sécurité Sanitaire de l'Environnement et du Travail (AFSSET; EST-2007-85) and Natural Sciences and Engineering Research Council of Canada (NSERC; Discovery grant 138195-2007 RGPIN) is acknowledged.

\section{References}

[1] Commission des communautés européennes, LIVRE BLANC Stratégie pour la future politique dans le domaine des substances chimiques, 2001.

[2] CEPA, "Loi canadienne sur la protection de l'environnement (1999), Règlement sur les renseignements concernant les substances nouvelles (substances chimiques et polymères)," in Gazette du Canada partie II, pp. 1850-2221, Queen's Printer for Canada, Ottawa, Canada, 2005.

[3] United States Environmental Protection Agency, "The U.S. Environmental Protection Agency's strategic plan for evaluating the toxicity of chemicals," Tech. Rep. EPA/100/K09/001, Office of the Science Advisor, Science Policy Council, Washington, DC, USA, 2009.

[4] K. Krishnan and M. E. Andersen, "Physiologically based pharmacokinetic modeling in toxicology," in Principles and Methods of Toxicology, A. W. Hayes, Ed., pp. 231-292, Taylor \& Francis, Boca Raton, Fla, USA, 2007.

[5] A. D. Arms and C. C. Travis, "Reference physiological parameters in pharmacokinetic modeling," Tech. Rep. EPA/600/688/004, United States Environmental Protection Agency, Washington, DC, USA, 1988.

[6] R. P. Brown, M. D. Delp, S. L. Lindstedt, L. R. Rhomberg, and R. P. Beliles, "Physiological parameter values for physiologically based pharmacokinetic models," Toxicology and Industrial Health, vol. 13, no. 4, pp. 407-484, 1997.

[7] M. Béliveau and K. Krishnan, "In Silico approaches for developing physiologically based pharmacokinetic (PBPK) models," in Alternative Toxicological Methods, H. Salem and S. A. Katz, Eds., pp. 479-532, CRC Press, Boca Raton, Fla, USA, 2003.

[8] T. Peyret and K. Krishnan, "QSARs for PBPK modelling of environmental contaminants," SAR and QSAR in Environmental Research, vol. 22, no. 1-2, pp. 129-169, 2011.

[9] J. DeJongh, H. J. M. Verhaar, and J. L. M. Hermens, "A quantitative property-property relationship (QPPR) approach to estimate in vitro tissue blood partition coefficients of organic chemicals in rats and humans," Archives of Toxicology, vol. 72, no. 1, pp. 17-25, 1997.

[10] P. Poulin and K. Krishnan, "An algorithm for predicting tissue: blood partition coefficients of organic chemicals from noctanol: water partition coefficient data," Journal of Toxicology and Environmental Health, vol. 46, no. 1, pp. 117-129, 1995.

[11] P. Poulin and K. Krishnan, "A biologically-based algorithm for predicting human tissue: blood partition coefficients of organic chemicals," Human and Experimental Toxicology, vol. 14, no. 3, pp. 273-280, 1995.
[12] P. Poulin and K. Krishnan, "A tissue composition-based algorithm for predicting tissue: air partition coefficients of organic chemicals," Toxicology and Applied Pharmacology, vol. 136, no. 1, pp. 126-130, 1996.

[13] P. Poulin and K. Krishnan, "A mechanistic algorithm for predicting blood: air partition coefficients of organic chemicals with the consideration of reversible binding in hemoglobin," Toxicology and Applied Pharmacology, vol. 136, no. 1, pp. 131137, 1996.

[14] P. Poulin and F. P. Theil, "A priori prediction of tissue:plasma partition coefficients of drugs to facilitate the use of physiologically-based pharmacokinetic models in drug discovery," Journal of Pharmaceutical Sciences, vol. 89, no. 1, pp. 16-35, 2000.

[15] P. Poulin and F. P. Theil, "Prediction of pharmacokinetics prior to in vivo studies. 1. Mechanism-based prediction of volume of distribution," Journal of Pharmaceutical Sciences, vol. 91, no. 1, pp. 129-156, 2002.

[16] T. Rodgers, D. Leahy, and M. Rowland, "Physiologically based pharmacokinetic modeling 1: predicting the tissue distribution of moderate-to-strong bases," Journal of Pharmaceutical Sciences, vol. 94, no. 6, pp. 1259-1276, 2005.

[17] T. Rodgers and M. Rowland, "Physiologically based pharmacokinetic modelling 2: predicting the tissue distribution of acids, very weak bases, neutrals and zwitterions," Journal of Pharmaceutical Sciences, vol. 95, no. 6, pp. 1238-1257, 2006.

[18] W. Schmitt, "General approach for the calculation of tissue to plasma partition coefficients," Toxicology in Vitro, vol. 22, no. 2, pp. 457-467, 2008.

[19] T. Peyret, P. Poulin, and K. Krishnan, "A unified algorithm for predicting partition coefficients for PBPK modeling of drugs and environmental chemicals," Toxicology and Applied Pharmacology, vol. 249, no. 3, pp. 197-207, 2010.

[20] P. Rydberg, U. Ryde, and L. Olsen, "Prediction of activation energies for aromatic oxidation by cytochrome P450," Journal of Physical Chemistry A, vol. 112, no. 50, pp. 13058-13065, 2008.

[21] D. Zhou, L. Afzelius, S. W. Grimm, T. B. Andersson, R. J. Zauhar, and I. Zamora, "Comparison of methods for the prediction of the metabolic sites for CYP3A4-mediated metabolic reactions," Drug Metabolism and Disposition, vol. 34, no. 6, pp. 976-983, 2006.

[22] C. Hansch, S. B. Mekapati, A. Kurup, and R. P. Verma, "QSAR of Cytochrome P450," Drug Metabolism Reviews, vol. 36, no. 1, pp. 105-156, 2004.

[23] D. F. V. Lewis, C. Sams, and G. D. Loizou, "A quantitative structure-activity relationship analysis on a series of alkyl benzenes metabolized by human cytochrome P450 2E1," Journal of Biochemical and Molecular Toxicology, vol. 17, no. 1, pp. 47-52, 2003.

[24] M. L. Gargas, P. G. Seybold, and M. E. Andersen, "Modeling the tissue solubilities and metabolic rate constant $V_{\max }$ of halogenated methanes, ethanes, and ethylenes," Toxicology Letters, vol. 43, no. 1-3, pp. 235-256, 1988.

[25] K. R. Korzekwa, J. P. Jones, and J. R. Gillette, "Theoretical studies on cytochrome P-450 mediated hydroxylation: a predictive model for hydrogen atom abstractions," Journal of the American Chemical Society, vol. 112, no. 19, pp. 7042-7046, 1990.

[26] H. Yin, M. W. Anders, K. R. Korzekwa et al., "Designing safer chemicals: predicting the rates of metabolism of halogenated alkanes," Proceedings of the National Academy of Sciences of the 
United States of America, vol. 92, no. 24, pp. 11076-11080, 1995.

[27] C. L. Waller, M. V. Evans, and J. D. Mckinney, "Modeling the cytochrome P450-mediated metabolism of chlorinated volatile organic compounds," Drug Metabolism and Disposition, vol. 24, no. 2, pp. 203-210, 1996.

[28] J. Ishizaki, K. Yokogawa, E. Nakashima, and F. Ichimura, "Relationships between the hepatic intrinsic clearance or blood cell-plasma partition coefficient in the rabbit and the lipophilicity of basic drugs," Journal of Pharmacy and Pharmacology, vol. 49, no. 8, pp. 768-772, 1997.

[29] D. F. V. Lewis, "Modelling human cytochromes P450 for evaluating drug metabolism: an update," Drug Metabolism and Drug Interactions, vol. 16, no. 4, pp. 307-324, 2000.

[30] D. F. V. Lewis, "Quantitative structure-activity relationships (QSARs) within the cytochrome P450 system: QSARs describing substrate binding, inhibition and induction of P450s," Inflammopharmacology, vol. 11, no. 1, pp. 43-73, 2003.

[31] J. P. Jones, M. Mysinger, and K. R. Korzekwa, "Computational models for cytochrome P450: a predictive electronic model for aromatic oxidation and hydrogen atom abstraction," Drug Metabolism and Disposition, vol. 30, no. 1, pp. 7-12, 2002.

[32] D. F. V. Lewis, "On the recognition of mammalian microsomal cytochrome P450 substrates and their characteristics: towards the prediction of human P450 substrate specificity and metabolism," Biochemical Pharmacology, vol. 60, no. 3, pp. 293-306, 2000.

[33] D. F. V. Lewis, S. Modi, and M. Dickins, "Structure-activity relationship for human cytochrome P450 substrates and inhibitors," Drug Metabolism Reviews, vol. 34, no. 1-2, pp. 69 82, 2002.

[34] K. V. Balakin, S. Ekins, A. Bugrim et al., "Quantitative structure-metabolism relationship modeling of metabolic Ndealkylation reaction rates," Drug Metabolism and Disposition, vol. 32, no. 10, pp. 1111-1120, 2004.

[35] S. Ekins, S. Andreyev, A. Ryabov et al., "Computational prediction of human drug metabolism," Expert Opinion on Drug Metabolism and Toxicology, vol. 1, no. 2, pp. 303-324, 2005.

[36] P. N. D’Yachkov, N. V. Kharchevnikova, A. V. Dmitriev, A. V. Kuznetsov, and V. V. Poroikov, "Quantum chemical simulation of cytochrome P450 catalyzed aromatic oxidation: metabolism, toxicity, and biodegradation of benzene derivatives," International Journal of Quantum Chemistry, vol. 107, no. 13, pp. 2454-2478, 2007.

[37] G. P. Miller, "Advances in the interpretation and prediction of CYP2E1 metabolism from a biochemical perspective," Expert Opinion on Drug Metabolism and Toxicology, vol. 4, no. 8, pp. 1053-1064, 2008.

[38] A. N. Mayeno, J. L. Robinson, R. S. H. Yang, and B. Reisfeld, "Predicting activation enthalpies of cytochrome-P450mediated hydrogen abstractions. 2. Comparison of semiempirical PM3, SAM1, and AM1 with a density functional theory method," Journal of Chemical Information and Modeling, vol. 49, no. 7, pp. 1692-1703, 2009.

[39] C. Gao, R. Goind, and H. H. Tabak, "Application of the group contribution method for predicting the toxicity of organic chemicals," Environmental Toxicology and Chemistry, vol. 11, no. 5, pp. 631-636, 1992.

[40] M. Béliveau, J. Lipscomb, R. Tardif, and K. Krishnan, "Quantitative structure-property relationships for interspecies extrapolation of the inhalation pharmacokinetics of organic chemicals," Chemical Research in Toxicology, vol. 18, no. 3, pp. 475-485, 2005.
[41] M. Béliveau, R. Tardif, and K. Krishnan, "Quantitative structure-property relationships for physiologically based pharmacokinetic modeling of volatile organic chemicals in rats," Toxicology and Applied Pharmacology, vol. 189, no. 3, pp. 221-232, 2003.

[42] E. Kamgang, T. Peyret, and K. Krishnan, "An integrated QSPRPBPK modelling approach for in vitro-in vivo extrapolation of pharmacokinetics in rats," SAR and QSAR in Environmental Research, vol. 19, no. 7-8, pp. 669-680, 2008.

[43] K. Price and K. Krishnan, "An integrated QSAR-PBPK modelling approach for predicting the inhalation toxicokinetics of mixtures of volatile organic chemicals in the rat," SAR and QSAR in Environmental Research, vol. 22, no. 1-2, pp. 107-128, 2011.

[44] W. M. Meylan and P. H. Howard, "Atom/fragment contribution method for estimating octanol-water partition coefficients," Journal of Pharmaceutical Sciences, vol. 84, no. 1, pp. 83-92, 1995.

[45] P. Poulin and K. Krishnan, "Molecular structure-based prediction of the toxicokinetics of inhaled vapors in humans," International Journal of Toxicology, vol. 18, no. 1, pp. 7-18, 1998.

[46] S. Haddad, G. C. Tardif, and R. Tardif, "Development of physiologically based toxicokinetic models for improving the human indoor exposure assessment to water contaminants: trichloroethylene and trihalomethanes," Journal of Toxicology and Environmental Health A, vol. 69, no. 23, pp. 2095-2136, 2006.

[47] N. Ali and R. Tardif, "Toxicokinetic modeling of the combined exposure to toluene and n-hexane in rats and humans," Journal of Occupational Health, vol. 41, no. 2, pp. 95-103, 1999.

[48] R. Tardif and G. Charest-Tardif, "The importance of measured end-points in demonstrating the occurrence of interactions: a case study with methylchloroform and m-xylene," Toxicological Sciences, vol. 49, no. 2, pp. 312-317, 1999.

[49] M. L. Gargas, M. E. Andersen, and H. J. Clewell III, "A physiologically based simulation approach for determining metabolic constants from gas uptake data," Toxicology and Applied Pharmacology, vol. 86, no. 3, pp. 341-352, 1986.

[50] J. C. Ramsey and M. E. Andersen, "A physiologically based description of the inhalation pharmacokinetics of styrene in rats and humans," Toxicology and Applied Pharmacology, vol. 73, no. 1, pp. 159-175, 1984.

[51] M. L. Gargas, H. J. Clewell III, and M. E. Andersen, "Metabolism of inhaled dihalomethanes in vivo: differentiation of kinetic constants for two independent pathways," Toxicology and Applied Pharmacology, vol. 82, no. 2, pp. 211223, 1986.

[52] J. G. Filser, G. A. Csanády, B. Denk et al., "Toxicokinetics of isoprene in rodents and humans," Toxicology, vol. 113, no. 13, pp. 278-287, 1996.

[53] S. Haddad, R. Tardif, G. Charest-Tardif, and K. Krishnan, "Physiological modeling of the toxicokinetic interactions in a quaternary mixture of aromatic hydrocarbons," Toxicology and Applied Pharmacology, vol. 161, no. 3, pp. 249-257, 1999.

[54] J. G. Filser, R. Schmidbauer, F. Rampf, C. M. Baur, C. Putz, and G. A. Csanady, "Toxicokinetics of inhaled propylene in mouse, rat, and human," Toxicology and Applied Pharmacology, vol. 169 , no. 1, pp. 40-51, 2000.

[55] M. L. Gargas, H. J. Clewell, and M. E. Andersen, "Gas uptake inhalation techniques and the rates of metabolism of chloromethanes, chloroethanes and chloroethylenes in the rat," Inhalation Toxicology, vol. 2, no. 3, pp. 295-319, 1990. 
[56] G. L. Kedderis and S. D. Held, "Prediction of furan pharmacokinetics from hepatocyte studies: comparison of bioactivation and hepatic dosimetry in rats, mice, and humans", Toxicology and Applied Pharmacology, vol. 140, no. 1, pp. 124130, 1996.

[57] R. H. Reitz, M. L. Gargas, A. L. Mendrala, and A. M. Schumann, "In vivo and in vitro studies of perchloroethylene metabolism for physiologically based pharmacokinetic modeling in rats, mice, and humans," Toxicology and Applied Pharmacology, vol. 136, no. 2, pp. 289-306, 1996.

[58] R. J. Williams, A. Vinegar, J. N. Mcdougal, A. M. Jarabek, and J. W. Fisher, "Rat to human extrapolation of HCFC-123 kinetics deduced from halothane kinetics: a corollary approach to physiologically based pharmacokinetic modeling," Fundamental and Applied Toxicology, vol. 30, no. 1, pp. 55-66, 1996.

[59] G. A. Csanády, B. Denk, C. Pütz et al., "A physiological toxicokinetic model for exogenous and endogenous ethylene and ethylene oxide in rat, mouse, and human: formation of 2hydroxyethyl adducts with hemoglobin and DNA," Toxicology and Applied Pharmacology, vol. 165, no. 1, pp. 1-26, 2000.

[60] J. E. Dennison, M. E. Andersen, and R. S. H. Yang, "Characterization of the pharmacokinetics of gasoline using PBPK modeling with a complex mixtures chemical lumping approach," Inhalation Toxicology, vol. 15, no. 10, pp. 961-986, 2003.

[61] A. M. Hissink, J. Krüse, B. M. Kulig et al., "Model studies for evaluating the neurobehavioral effects of complex hydrocarbon solvents. III. PBPK modeling of white spirit constituents as a tool for integrating animal and human test data," NeuroToxicology, vol. 28, no. 4, pp. 751-760, 2007.

[62] D. F. V. Lewis, Guide to Cytochromes P450: Structure and Function, Taylor \& Francis, London, UK, 2001.

[63] A. I. Archakov and G. I. Bachmanova, Eds., Cytochrome P-450 and Active Oxygen, Taylor \& Francis, London, UK, 1990.

[64] Z. Fang, J. Sonner, M. J. Laster et al., "Anesthetic and convulsant properties of aromatic compounds and cycloalkanes: implications for mechanisms of narcosis," Anesthesia and Analgesia, vol. 83, no. 5, pp. 1097-1104, 1996.

[65] P. D. Lilly, M. E. Andersen, T. M. Ross, and R. A. Pegram, "Physiologically based estimation of in vivo rates of bromodichloromethane metabolism," Toxicology, vol. 124, no. 2, pp. 141-152, 1997.

[66] M. L. Gargas, R. J. Burgess, D. E. Voisard, G. H. Cason, and M. E. Andersen, "Partition coefficients of low-molecular-weight volatile chemicals in various liquids and tissues," Toxicology and Applied Pharmacology, vol. 98, no. 1, pp. 87-99, 1989.

[67] R. Tardif, G. Charest-Tardif, J. Brodeur, and K. Krishnan, "Physiologically based pharmacokinetic modeling of a ternary mixture of alkyl benzenes in rats and humans," Toxicology and Applied Pharmacology, vol. 144, no. 1, pp. 120-134, 1997.

[68] M. Béliveau and K. Krishnan, "Estimation of rat blood: air partition coefficients of volatile organic chemicals using reconstituted mixtures of blood components," Toxicology Letters, vol. 116, no. 3, pp. 183-188, 2000.

[69] C. Hansch and L. Zhang, "Quantitative structure-activity relationships of cytochrome P-450," Drug Metabolism Reviews, vol. 25, no. 1-2, pp. 1-48, 1993.

[70] D. F. V. Lewis and M. Dickins, "Baseline lipophilicity relationships in human cytochromes P450 associated with drug metabolism," Drug Metabolism Reviews, vol. 35, no. 1, pp. 118, 2003.

[71] D. F. V. Lewis and Y. Ito, "Human P450s involved in drug metabolism and the use of structural modelling for understanding substrate selectivity and binding affinity," Xenobiotica, vol. 39, no. 8, pp. 625-635, 2009.

[72] L. B. Kier, "A shape index from molecular graphs," Quantitative Structure-Activity Relationships, vol. 4, no. 3, pp. 109-116, 1985.

[73] Organisation for Economic Co-operation and Development, "Guidance document on the validation of (quantitative) structure-activity relationship [(Q)SAR] models," Tech. Rep., OECD-OCDE, Paris, France, 2007, OECD Environment Health and Safety Publications, Editor.

[74] P. Gramatica, "Principles of QSAR models validation: Internal and external," QSAR and Combinatorial Science, vol. 26, no. 5, pp. 694-701, 2007.

[75] S. A. Glantz and B. K. Slinker, Primer of Applied Regression and Analysis of Variance, McGraw-Hill, New York, NY, USA, 2nd edition, 2001.

[76] S. Wold, "Validation of QSARs," Quantitative Structure Activity Relashionship, vol. 10, pp. 191-193, 1991.

[77] C. J. W. Meulenberg and H. P. M. Vijverberg, "Empirical relations predicting human and rat tissue: air partition coefficients of volatile organic compounds," Toxicology and Applied Pharmacology, vol. 165, no. 3, pp. 206-216, 2000.

[78] S. Batterman, L. Zhang, S. Wang, and A. Franzblau, "Partition coefficients for the trihalomethanes among blood, urine, water, milk and air," Science of the Total Environment, vol. 284, no. 1-3, pp. 237-247, 2002.

[79] L. M. da Silva, G. Charest-Tardif, K. Krishnan, and R. Tardif, "Influence of oral administration of a quaternary mixture of trihalomethanes on their blood kinetics in the rat," Toxicology Letters, vol. 106, no. 1, pp. 49-57, 1999.

[80] M. E. Andersen, H. J. Clewell, M. L. Gargas, F. A. Smith, and R. H. Reitz, "Physiologically based pharmacokinetics and the risk assessment process for methylene chloride," Toxicology and Applied Pharmacology, vol. 87, no. 2, pp. 185-205, 1987.

[81] J. C. Ramsey, J. D. Young, R. J. Karbowski, M. B. Chenoweth, L. P. McCarty, and W. H. Braun, "Pharmacokinetics of inhaled styrene in human volunteers," Toxicology and Applied Pharmacology, vol. 53, no. 1, pp. 54-63, 1980.

[82] M. E. Andersen, H. J. Clewell, M. L. Gargas et al., "Physiologically based pharmacokinetic modeling with dichloromethane, its metabolite, carbon monoxide, and blood carboxyhemoglobin in rats and humans," Toxicology and Applied Pharmacology, vol. 108, no. 1, pp. 14-27, 1991.

[83] T. M. Cahill, I. Cousins, and D. Mackay, "Development and application of a generalized physiologically based pharmacokinetic model for multiple environmental contaminants," Environmental Toxicology and Chemistry, vol. 22, no. 1, pp. 2634, 2003.

[84] International Programme on Chemical Safety, Characterization and Application of Physiologically Based Pharmacokinetic Models in Risk Assessment, International Programme on Chemical Safety, 2010.

[85] C. J. MacKay, L. Campbell, A. M. Samuel et al., "Behavioral changes during exposure to 1,1,1-trichloroethane: timecourse and relationship to blood solvent levels," American Journal of Industrial Medicine, vol. 11, no. 2, pp. 223-239, 1987.

[86] M. T. D. Cronin and D. Livingstone, Predicting Chemical Toxicity and Fate, CRC Press, Boca Raton, Fla, USA, 2004.

[87] H. Gao and C. Hansch, "QSAR of P450 oxidation: on the value of comparing kcat and km with kcat/km," Drug Metabolism Reviews, vol. 28, no. 4, pp. 513-526, 1996. 
[88] J. P. Jones, K. R. Korzekwa, F. J. Eric, and R. W. Michael, "Predicting the rates and regioselectivity of reactions mediated by the P450 superfamily," in Methods in Enzymology, pp. 326335, Academic Press, New York, NY, USA, 1996.

[89] D. L. Harris, J.-Y. Park, L. Gruenke, and L. Waskell, “Theoretical study of the ligand-CYP2B4 complexes: effect of structure on binding free energies and heme spin state," Proteins, vol. 55, no. 4, pp. 895-914, 2004.

[90] L. Olsen, P. Rydberg, T. H. Rod, and U. Ryde, "Prediction of activation energies for hydrogen abstraction by cytochrome P450," Journal of Medicinal Chemistry, vol. 49, no. 22, pp. 6489-6499, 2006.

[91] D. N. Kim, K. H. Cho, W. S. Oh et al., "EaMEAD: activation energy prediction of cytochrome $\mathrm{p} 450$ mediated metabolism with effective atomic descriptors," Journal of Chemical Information and Modeling, vol. 49, no. 7, pp. 1643-1654, 2009.

[92] Y. Lu, S. Rieth, M. Lohitnavy et al., "Application of PBPK modeling in support of the derivation of toxicity reference values for 1-trichloroethane," Regulatory Toxicology and Pharmacology, vol. 50, no. 2, pp. 249-260, 2008.

[93] R. H. Reitz, J. N. McDougal, M. W. Himmelstein, R. J. Nolan, and A. M. Schumann, "Physiologically based pharmacokinetic modeling with methylchloroform: implications for interspecies, high dose/low dose, and dose route extrapolations," Toxicology and Applied Pharmacology, vol. 95, no. 2, pp. 185199, 1988.

[94] M. H. Wang, D. Wade, L. Chen, S. White, and C. S. Yang, "Probing the active sites of rat and human cytochrome P450 2E1 with alcohols and carboxylic acids," Archives of Biochemistry and Biophysics, vol. 317, no. 1, pp. 299-304, 1995. 

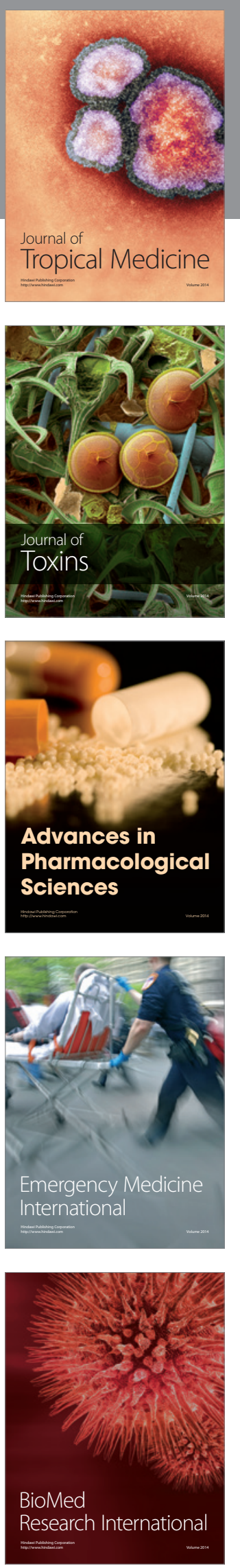
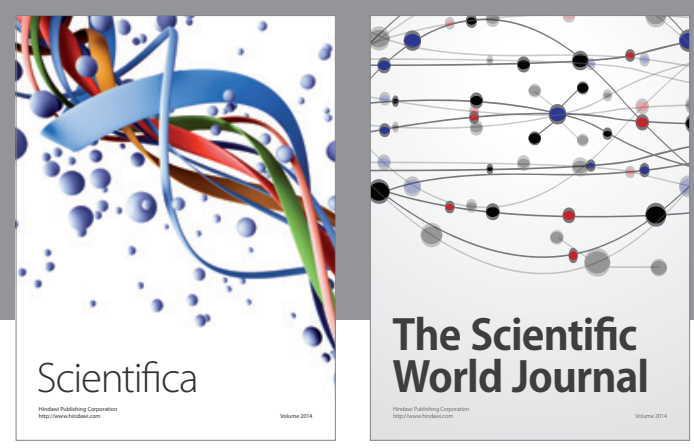

The Scientific World Journal
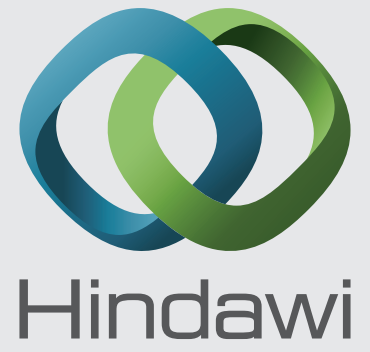

Submit your manuscripts at

http://www.hindawi.com
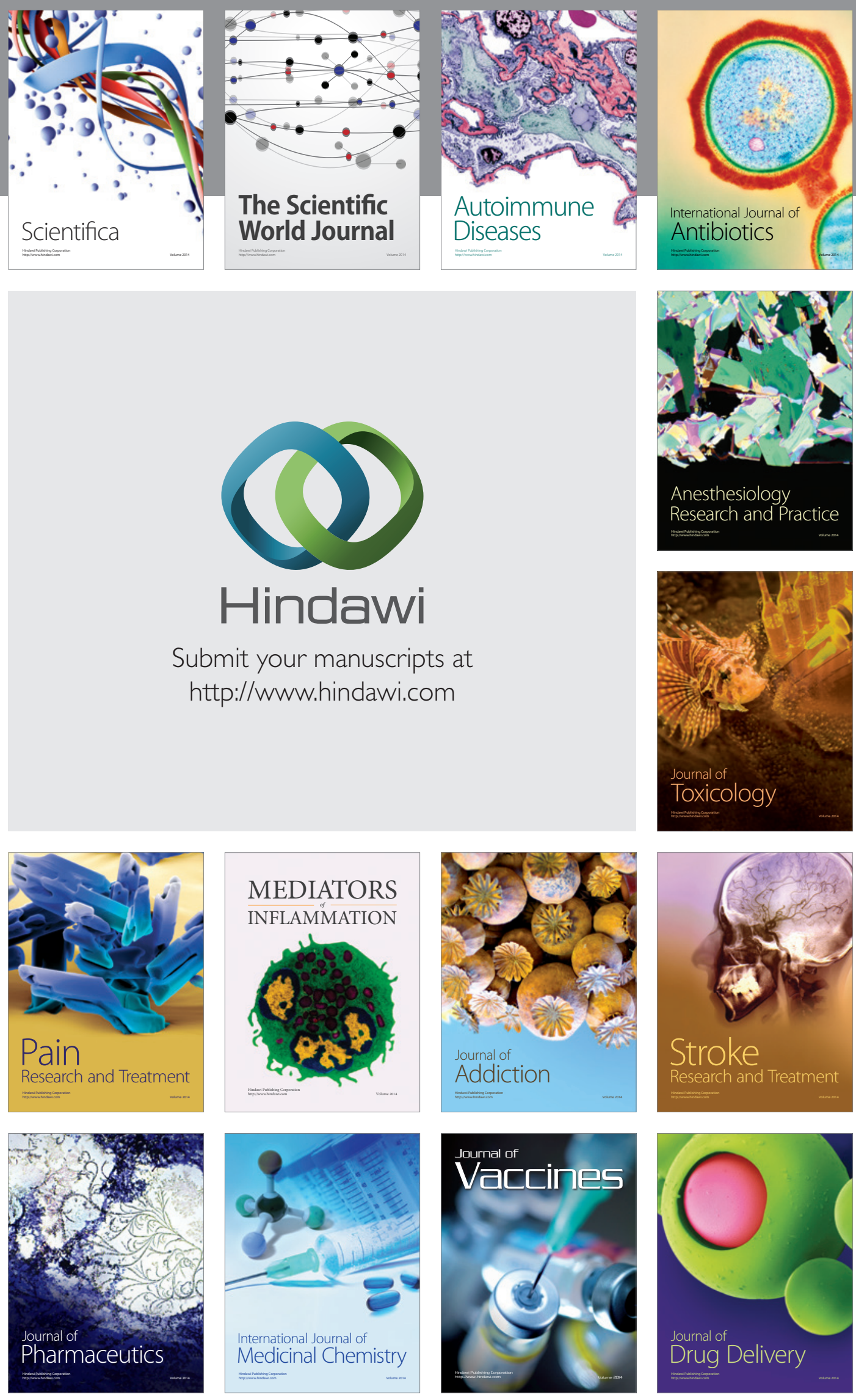